University of South Florida

DIGITAL COMMONS

@ UNIVERSITY OF SOUTH FLORIDA
Digital Commons @ University of

South Florida

$7-1-2008$

\title{
Creative Ways to Manage Paratransit Costs
}

CUTR

Follow this and additional works at: https://digitalcommons.usf.edu/cutr_nctr

\section{Recommended Citation}

"Creative Ways to Manage Paratransit Costs," National Center for Transit Research (NCTR) Report No. CUTR-NCTR-RR-2005-10, Center for Urban Transportation Research, University of South Florida, 2008. DOI: https://doi.org/10.5038/CUTR-NCTR-RR-2005-10

Available at: https://scholarcommons.usf.edu/cutr_nctr/161

This Technical Report is brought to you for free and open access by the National Center for Transit Research (NCTR) Archive (2000-2020) at Digital Commons @ University of South Florida. It has been accepted for inclusion in Research Reports by an authorized administrator of Digital Commons @ University of South Florida. For more information, please contact digitalcommons@usf.edu. 


\title{
Creative Ways to Manage Paratransit Costs
}

\author{
Project \#BD549-28
}

\section{FINAL REPORT}

Prepared for the

Florida Department of Transportation

Research Center

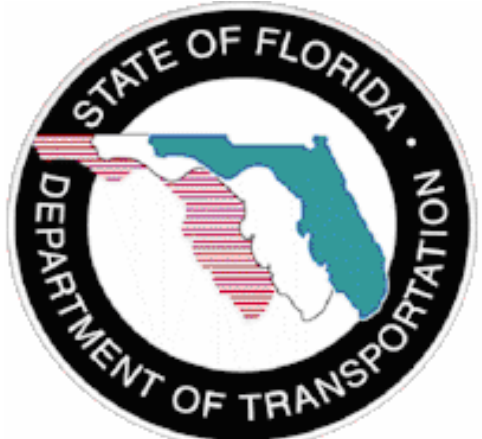

Prepared by the

Center for Urban Transportation Research University of South Florida

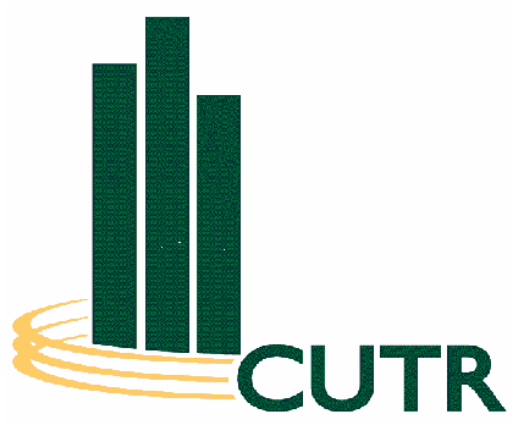

July 2008 


\section{Disclaimer}

The opinions, findings, and conclusions expressed in this publication are those of the authors and not necessarily those of the State of Florida Department of Transportation. 


\begin{tabular}{|c|c|c|c|c|}
\hline $\begin{array}{l}\text { 1. Report No. } \\
\text { BD } 549 \text { RPWO } 28\end{array}$ & \multicolumn{2}{|c|}{ 2. Government Accession No. } & \multicolumn{2}{|c|}{ 3. Recipient's Catalog No. } \\
\hline \multicolumn{3}{|l|}{ 4. Title and Subtitle } & \multicolumn{2}{|l|}{$\begin{array}{l}\text { 5. Report Date } \\
\text { July } 2008\end{array}$} \\
\hline \multicolumn{3}{|c|}{ Creative Ways to Manage Paratransit Costs } & \multicolumn{2}{|c|}{ 6. Performing Organization Code } \\
\hline \multicolumn{3}{|c|}{$\begin{array}{l}\text { 7. Author(s) } \\
\text { Jay A. Goodwill, P.E., CCTM } \\
\text { Holly Carapella }\end{array}$} & \multicolumn{2}{|c|}{ 8. Performing Organization Report No. } \\
\hline \multicolumn{3}{|c|}{$\begin{array}{l}\text { 9. Performing Organization Name and Address } \\
\text { National Center For Transit Research (NCTR) }\end{array}$} & \multicolumn{2}{|c|}{ 10. Work Unit No. (TRAIS) } \\
\hline \multicolumn{3}{|c|}{$\begin{array}{l}\text { Center for Urban Transportation Research } \\
\text { University of South Florida - CUT } 100 \\
4202 \text { East Fowler Avenue, Tampa, FL } 33620\end{array}$} & \multicolumn{2}{|l|}{ BD 549-28 } \\
\hline \multirow{2}{*}{\multicolumn{3}{|c|}{$\begin{array}{l}\text { 12. Sponsoring Agency Name and Address } \\
\text { Office of Research and Special Programs (RSPA) } \\
\text { U.S. Department of Transportation, Washington, D.C. 2C } \\
\text { Florida Department of Transportation } \\
605 \text { Suwannee Street, MS 26, Tallahassee, FL } 32399\end{array}$}} & \multicolumn{2}{|c|}{$\begin{array}{l}\text { 13. Type of Report and Period Covered } \\
\text { Final Report }\end{array}$} \\
\hline & & & \multicolumn{2}{|c|}{ 14. Sponsoring Agency Code } \\
\hline \multicolumn{5}{|l|}{ 15. Supplementary Notes } \\
\hline \multirow{2}{*}{\multicolumn{5}{|c|}{$\begin{array}{l}\text { 16. Abstract } \\
\text { As communities continue to move toward providing a wide range of public transportation } \\
\text { services - often referred to as the "family of services" - one common concern is the rising } \\
\text { costs of providing services, specifically those falling under the paratransit umbrella. Although } \\
\text { paratransit services are usually the most efficient way to provide specialized needs or life } \\
\text { sustaining service for the most vulnerable citizens, they are typically the most expensive, least } \\
\text { available, and most difficult to coordinate. Cities, counties, states, and other transportation } \\
\text { agencies that provide or purchase paratransit services are continually pursuing methods to } \\
\text { contain, control or reduce paratransit costs. } \\
\text { The purpose of this project was to define types of paratransit services and their } \\
\text { characteristics, document major paratransit expense factors and their trends, and identify and } \\
\text { document best practices in paratransit cost containment. }\end{array}$}} \\
\hline & & & & \\
\hline \multicolumn{2}{|c|}{$\begin{array}{l}\text { 17. Key Word } \\
\text { Public transportation, paratransit, cost } \\
\text { management, specialized transportation }\end{array}$} & \multicolumn{3}{|c|}{$\begin{array}{l}\text { 18. Distribution Statement } \\
\text { Available to the public through the National } \\
\text { Technical Information Service (NTIS), } 5285 \\
\text { Port Royal Road, Springfield, VA 22161, } \\
\text { (703) 487-4650, http://www.rtis.gov/ , and } \\
\text { through the NCTR web site at } \\
\text { http://www.cutr.usf.edu/ }\end{array}$} \\
\hline $\begin{array}{l}\text { 19. Security Classif. (of this } \\
\text { Unclassified }\end{array}$ & 20. Security & $\begin{array}{l}\text { (of this page) } \\
\text { ssified }\end{array}$ & \begin{tabular}{l|l|}
$\begin{array}{l}\text { 21. No. of } \\
\text { Pages }\end{array} 94$ \\
\end{tabular} & $\begin{array}{l}\text { 22. Price } \\
\text { No Cost }\end{array}$ \\
\hline
\end{tabular}




\section{Executive Summary}

The Transportation Research Board's Committee on Paratransit states that paratransit means alongside transit. This includes all public and private mass transportation in the spectrum between private automobiles and conventional transit. Paratransit modes are usually demand responsive and provide shared rides.

With the passage of the Americans with Disabilities Act of 1990 (ADA), the traditional delivery of paratransit services by social service agencies changed. The passage of the ADA and its requirements to provide complementary paratransit services put all public transit operators in the paratransit business. The resultant changes in organizational structures, internal procedures, and the use of technology have reduced the distinction between fixed route and paratransit services.

As communities continue to move toward providing a wide range of public transportation services - often referred to as the family of services - one common concern is the rising costs of providing services, specifically those falling under the paratransit umbrella. Although paratransit services are usually the most efficient way to provide specialized needs or life sustaining service for the most vulnerable citizens, they are typically the most expensive, often limited in their availability, and most difficult to coordinate. Cities, counties, states and other transportation agencies that provide or purchase paratransit services are continually pursuing methods to contain, control or reduce paratransit costs.

The purpose of this project was to define types of paratransit services and their characteristics, document major paratransit expense factors and their trends, and identify and document best practices of paratransit cost containment.

An early task in this research effort was to conduct a literature review of previous studies and reports related to paratransit issues, specifically those related to the management and budgeting of paratransit operations. 
One task of the research was to identify the major expense categories for paratransit services and factors impacting these cost centers. The objective was not only to ascertain the most significant expense categories but also to document the changes in cost by categories over time. The two primary sources of financial data utilized were the National Transit Database (NTD) reports and the Florida Commission for the Transportation Disadvantaged Annual Operating Reports. Using these two data sources, the trends in the costs of providing paratransit services and the major expense categories and factors impacting these cost centers were identified and documented for Florida public paratransit systems.

Another element of the research was to identify the existing practices of Florida's transit systems and the efforts directed toward managing and containing paratransit costs. This was accomplished with a survey targeting Florida's fixed route transit systems operating complementary ADA paratransit services.

When this research project was initiated, it was hoped that some critical insight into the cost factors of providing paratransit services would be uncovered, leading to the discovery of innovative and breakthrough cost containment strategies. These hopes and aspirations, however, were not realized. While the major cost components of paratransit services were identified, the strategies and best practices for managing the costs of paratransit services came down the application of good management policies and practices, a comprehensive approach to address multiple cost-containment strategies, and ongoing and continuous vigilance of the process.

The report concludes with a summary of the best practices that were identified for managing and containing the costs of providing paratransit services. These strategies and practices are organized by topical areas and presented in abbreviated format so as not to repeat the background presented in the previous chapters. 


\section{Table of Contents}

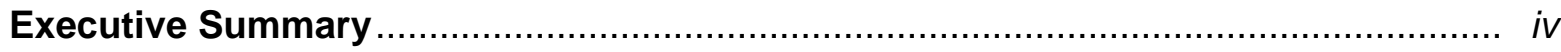

Table of Contents

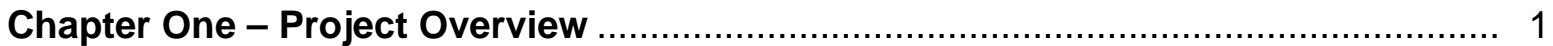

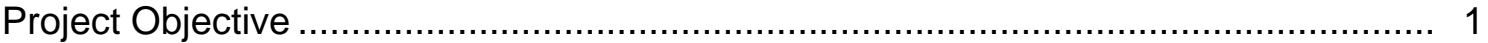

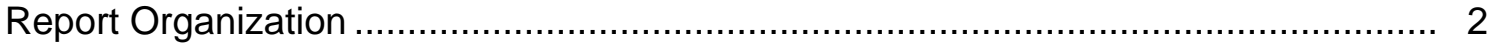

Chapter Two - Literature Review ……………............................................. 3

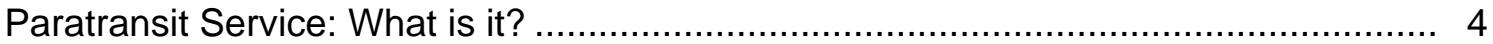

Costs of Providing Paratransit Services .......................................................... 4

Strategies to Control the Costs of Paratransit Service ............................................. 5

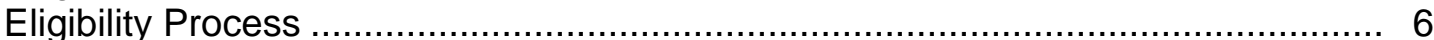

Reservation/Scheduling /Dispatch Process ................................................... 7

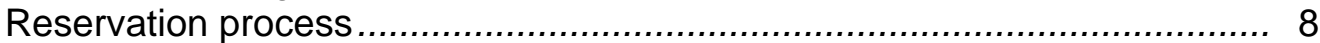

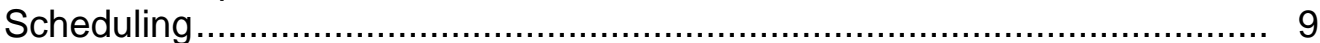

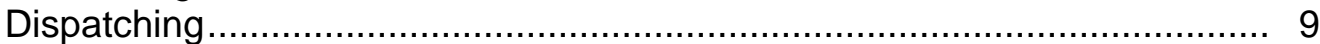

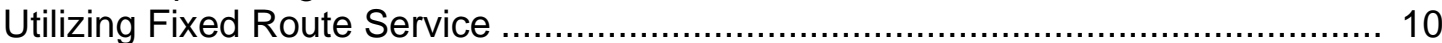

Providing Accessible Information on Fixed-Route System .......................... 11

Bus Stop Accessibility ...................................................................... 11

Automated Stop Announcements............................................................ 11

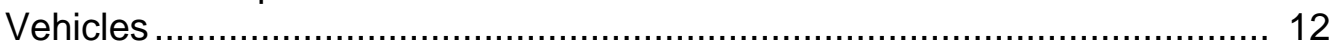

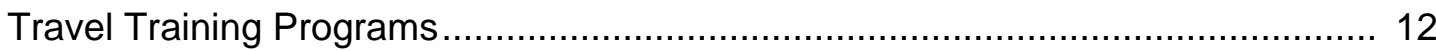

Coordination with other Transportation Providers ............................................. 13

Chapter Three - Expense Categories and Trends ............................................. 16

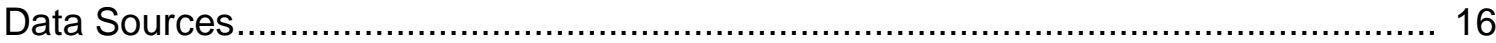

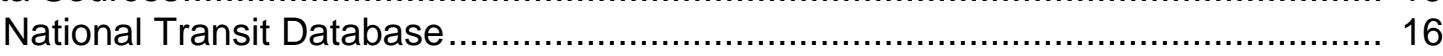

Annual Operating Reports ............................................................................ 17

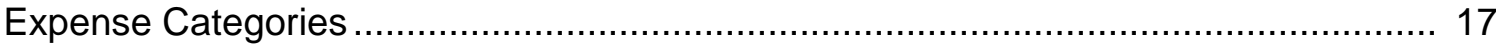

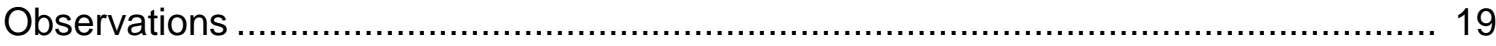

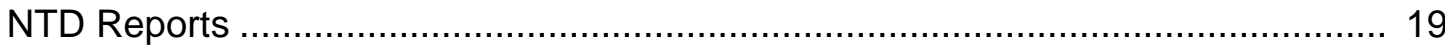

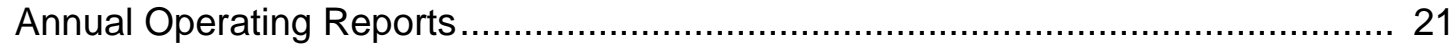

Chapter Four - Examination of Exiting Practices.................................................... 24

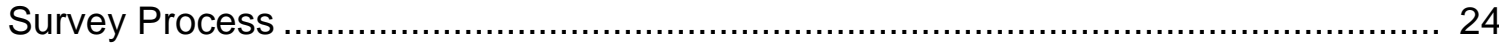

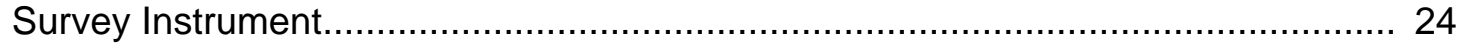

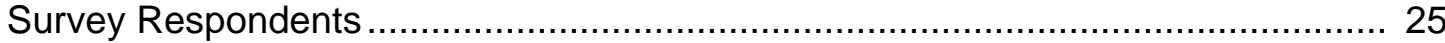

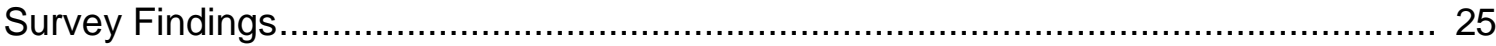

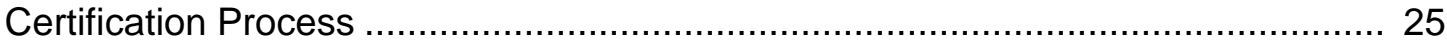

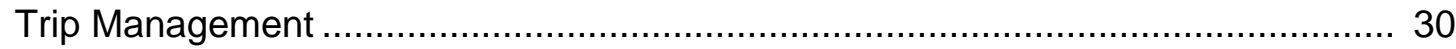

No Show and Late Cancellation Practices ………………............................... 36

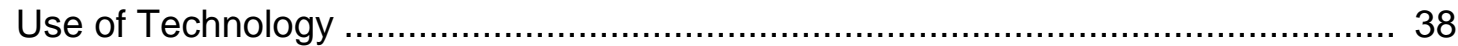

Travel Training and Use of Fixed Route System............................................... 40

Volunteer Programs .................................................................................. 42 


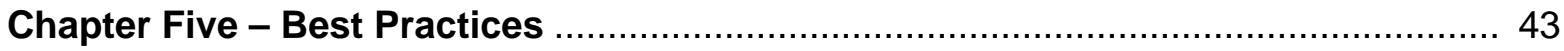

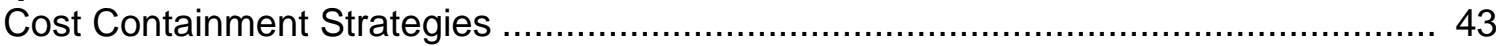

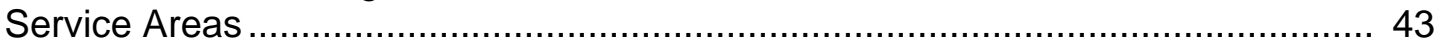

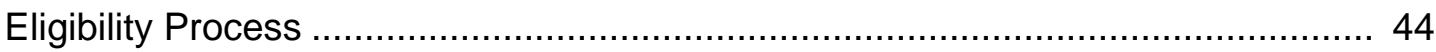

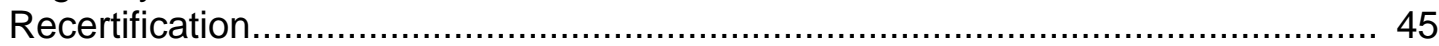

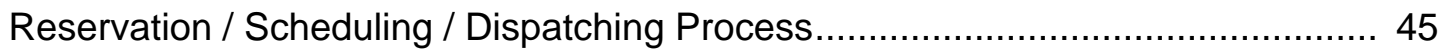

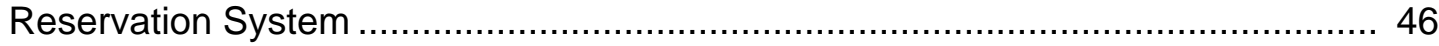

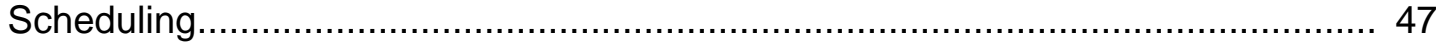

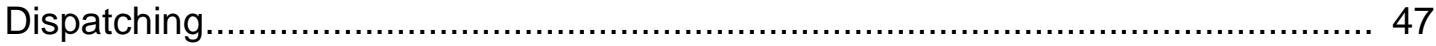

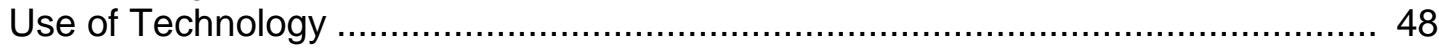

No Shows and Late Cancellation Policies ................................................. 50

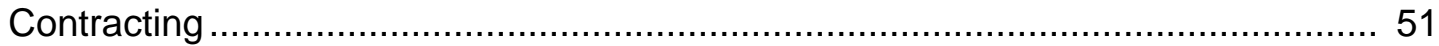

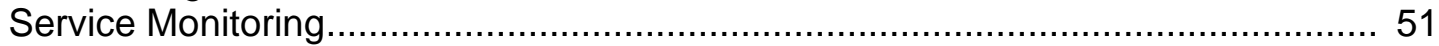

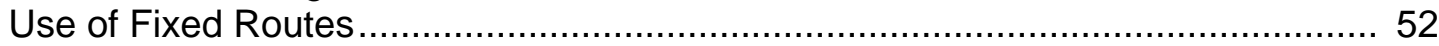

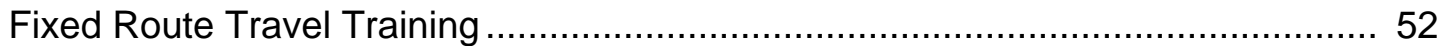

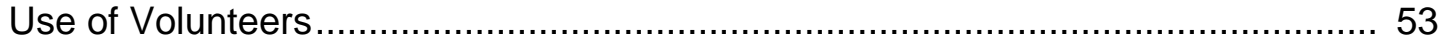

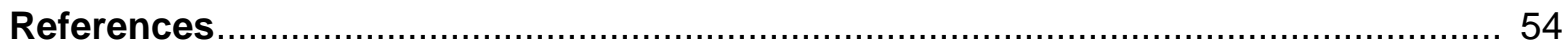

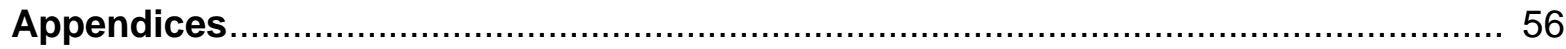

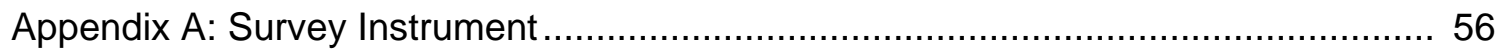

Appendix B: Sample of a Ride Guide ............................................................... 62 


\section{List of Exhibits}

1 - Savings Realized by Moving from Paratransit to Fixed Route Service ............. 10

2 - Annual Operating Report Expense Categories .............................................. 18

3 - Paratransit Annual Expense Trends........................................................... 19

4 - Six Year Trend in Annual Changes in Paratransit Expenses ............................ 20

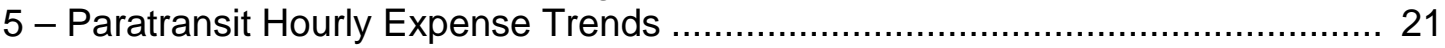

6 - Florida TD System Expense Components ................................................... 22

7 - Florida TD System Average Expense Components ...................................... 23

8 - Florida Fixed Route Transit Systems Responding to Survey ........................... 25

9 - Changes in Paratransit Eligibility Application ................................................ 26

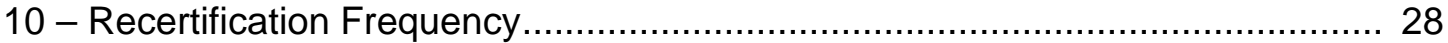

11 - In-Person ADA Functional Assessments ................................................ 29

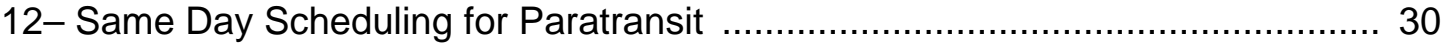

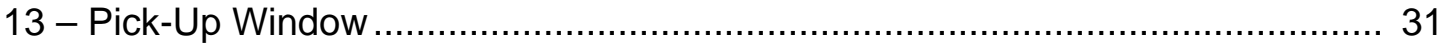

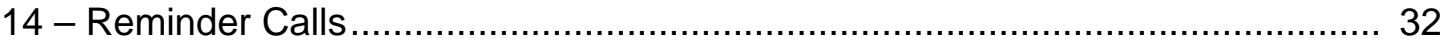

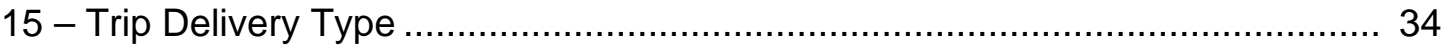

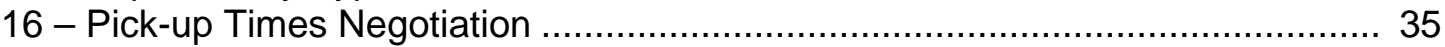

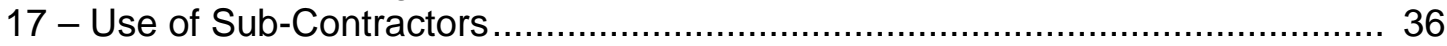

18 - No-Show and Late Cancellation Practices ................................................ 38

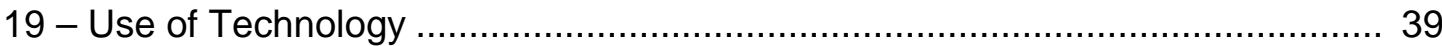

20 - Type of Paratransit Scheduling Software ..................................................... 39

21- Free and Subsidized Fixed Route Pass Practices ....................................... 40

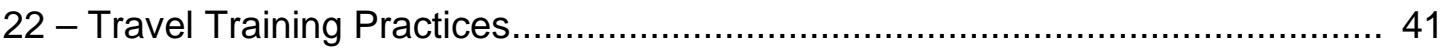

23- Use of Volunteers ............................................................................... 42 


\section{Chapter One \\ Project Overview}

\section{Project Objective}

The Transportation Research Board's Committee on Paratransit states that paratransit means alongside transit. This includes all public and private mass transportation in the spectrum between private automobiles and conventional transit. Paratransit modes are usually demand responsive and provide shared rides.

With the passage of the Americans with Disabilities Act of 1990 (ADA), the traditional delivery of paratransit services by social service agencies changed. The passage of the ADA and its requirements to provide complementary paratransit services put all public transit operators in the paratransit business. The resultant changes in organizational structures, internal procedures, and the use of technology have reduced the distinction between fixed route and paratransit services.

As communities continue to move toward providing a wide range of public transportation services - often referred to as the family of services - one common concern is the rising costs of providing services, specifically those falling under the paratransit umbrella. Although paratransit services are usually the most efficient way to provide specialized needs or life sustaining service for the most vulnerable citizens, they are typically the most expensive, often limited in their availability, and most difficult to coordinate. Cities, counties, states and other transportation agencies that provide or purchase paratransit services are continually pursuing methods to contain, control or reduce paratransit costs.

The purpose of this project was to define types of paratransit services and their characteristics, document major paratransit expense factors and their trends, and identify and document best practices of paratransit cost containment. 


\section{Report Organization}

An early task in this research effort was to conduct a literature review of previous studies and reports related to paratransit issues, specifically those related to the management and budgeting of paratransit operations. Chapter Two provides a review and summary of the relevant findings.

The literature review allowed researchers to become more knowledgeable about topics related to paratransit and provided guidance in preparation for the survey, which was developed and distributed to all Florida public paratransit service providers. The survey, which is detailed in Chapter Four, was designed to identify existing practices and efforts undertaken at a local level to manage and contain paratransit costs.

One task of the research was to identify the major expense categories for paratransit services and factors impacting these cost centers. The objective was not only to ascertain the most significant expense categories but also to document the changes in cost by categories over time. The two primary sources of financial data utilized were the National Transit Database (NTD) reports and the Florida Commission for the Transportation Disadvantaged Annual Operating Reports. Using these two data sources, the trends in the costs of providing paratransit services and the major expense categories and factors impacting these cost centers were identified and documented for Florida public paratransit systems. Chapter Three provides a review and summary of the relevant findings.

Another element of the research was to identify the existing practices of Florida's transit systems and the efforts directed toward managing and containing paratransit costs. This was accomplished with a survey targeting Florida's fixed route transit systems operating complementary ADA paratransit services. Chapter Four provides a review and summary of the relevant findings.

Chapter Five provides a summary of the best practices that were identified for managing and containing the costs of providing paratransit services. 


\section{Chapter Two}

\section{Literature Review}

A literature review of previous studies and reports related to paratransit issues, specifically those related to the management and budgeting of paratransit operations was conducted. This chapter provides a review and summary of the relevant findings.

The literature review allowed researchers to become more knowledgeable about topics related to paratransit and provided guidance in preparation for the survey, which was developed and distributed to all Florida public paratransit service providers. The survey, which is detailed in Chapter Four, was designed to identify existing practices and efforts undertaken at a local level to manage and contain paratransit costs.

Extensive literature searches were conducted using the TRIS literature database made available by the Transportation Research Board and the resource library at the USF Center for Urban Transportation Research (CUTR). Every attempt was made to obtain and review the most current literature available. All literature was reviewed for relevancy to the topic and summarized. The literature reviewed addressed a variety of issues facing transit agencies providing paratransit services. The results of this literature review were synthesized into the three major categories listed below.

- Identifying the different types of paratransit services

- Understanding the costs of providing paratransit services

- Identifying strategies being used to control and reduce costs of paratransit service

These categories are presented in the following order. The first section provides an overview of the different types of paratransit services existing within the transit industry. Second, a discussion of the costs involved with providing paratransit services will be presented. Finally, the third section presents a review of strategies and programs found to be useful in controlling and reducing the costs of providing paratransit service. This third section introduces innovative and successful programs being utilized by transit agencies to control the costs of providing paratransit services. 


\section{Paratransit Service: What is it?}

The Transportation Research Board's Committee on Paratransit states that "paratransit" means alongside transit. It includes all public and private mass transportation in the spectrum between private automobile and conventional transit. Paratransit modes are usually demand responsive and provide shared rides.

According to the American Public Transportation Association (APTA), there are three types of paratransit service: complementary, general, and user-side subsidy service.

Complementary paratransit service is required under the Americans with Disabilities Act of 1990 for persons not capable of using an existing fixed-route service. Generally, complementary ADA paratransit service is provided to those persons with physical or mental disabilities who are unable to use fixed-route service. Complementary ADA paratransit service is provided to those meeting eligibility requirements, and provides trips only with origins and destinations within $3 / 4$ mile of the existing fixed-route service. Generally, it must operate during the same hours the fixed-route service operates. Fares charged for complementary ADA paratransit service fares can not be more then double the comparable fixed-route fares.

General paratransit service is not required under federal law and is not subject to the requirements imposed on complementary paratransit service. Local jurisdiction can provide the service to certain populations (elderly, children, low-income residents) or can provide general paratransit service to all of the local population. General paratransit service also can be operated when the existing fixed-route service does not -- for example, on nights and/or weekends in some locations.

The third type of paratransit service provided is often referred to as a user-side subsidy service. This service can be partially subsidized by the transit agency and often is operated through private transportation providers (taxicabs/vans) and/or a partial or complete brokerage system, which may charge a fee per ride based on the rider's eligibility for services defined in the local operating area.

\section{Costs of Providing Paratransit Services}

In comparison to the cost of a fixed-route passenger trip, paratransit trips are considerably more expensive - often up from 7 to 10 times more expensive per trip provided. While fixed-route service is most cost-effective in densely populated urban environments, in developing areas and 
more sprawling metropolitan areas, the cost of using paratransit service to provide public transportation services may be competitive or actually lower that attempting to serve these markets with fixed-route service.

Factors that contribute to the overall cost of delivering of paratransit trips include developing, staffing, and operating a paratransit department. Operators need to be hired and given specialized training for assisting in the needs to passengers, wheelchair securement, and licensing requirements. Specialized vehicles (e.g., lift-equipped vans and cutaway buses) are required to provide trips to those physically unable to use fixed-route buses. Implementing technology to ease the coordination and delivery of paratransit services also adds to the cost. However, by utilizing available technologies including mobile data terminals (MDT), computers, vehicle locator devices, geographic information systems, smart card technologies, and computerized scheduling and dispatching software, service can be provided more efficiently and overall costs can be lowered.

Due to the complexities of providing paratransit service, many transit agencies elect to contract out some or all of their paratransit operations. According to data from APTA, it was found that more than 50 percent of expenditures for demand response services were paid to third-party contractors providing paratransit service.

\section{Strategies to Control the Costs of Paratransit Service}

The provision of paratransit service can be costly. However, there have been studies undertaken and programs implemented that point toward ways of reducing and controlling the costs of providing paratransit services. Programs and approaches have been identified and utilized by transit agencies that actually do help control and contain the costs of providing paratransit trips. These methods include:

- Developing and implementing a localized paratransit eligibility process with strict criteria

- Developing a functional reservations/scheduling/dispatching process

- Working to shift patrons toward fixed route service

- Providing travel training services to patrons and proper training for employees

- Coordination with other area transportation providers

- Standardization of fleets to minimize inventory costs

- Traditional labor management techniques to maximize productivity and efficiencies 
In the following section, these methods will be discussed, and examples of how transit agencies are using these methods to control the overall costs of providing paratransit services will be outlined.

\section{Eligibility Process}

General community paratransit services are often targeted and limited to specific population groups such as senior citizens, disabled residents, or specific economic segments. In such instances, the transit provider needs to develop a process to certify the patrons' eligibility to qualify for the paratransit services. In most cases, the transit provider or sponsoring agency has fairly wide leeway in setting eligibility parameters and the process.

Paratransit trips provided as part of the ADA complementary paratransit requirements are subject to some very specific standards that must be accommodated in the eligibility process.

Under the ADA complementary paratransit regulations, a transit provider must provide paratransit services comparable to their regular fixed-route system for individuals who are certified as ADA paratransit eligible. ADA paratransit eligibility is based upon functional abilities rather than medical diagnoses. An individual will be certified as eligible if there is any part of the fixed-route system the person cannot use or navigate because of a disability or condition. Some individuals may be eligible for paratransit service under very specific conditions, which permits transit agencies to determine eligibility on a trip-by-trip basis.

For most transit agencies, to be considered ADA eligible, a passenger must fit into one of the following categories:

- A condition or disability must prevent a person from getting on or off a regular fixed-route bus

- A condition or disability must prevent a person from getting to or from a regular bus stop that is within $3 / 4$ mile of your location

- A condition or disability must prevent a person from waiting at a regular fixed-route bus stop

- A condition or disability must prevent a person from being able to ride the fixed-route buses or to understand and follow transit instructions

Transit agencies have a variety of options to determine if a passenger is eligible to utilize paratransit services. An applicant is usually required to submit a standard paper application. An in-person interview is often required by the transit agency and sometimes a functional assessment, which is an in-person evaluation of the ability of the passenger to ride a fixed-route 
bus is also required. A medical verification is usually required to complement the application process.

For example, Dial a Ride Community Transit (DART) of Snohomish County (Washington) provides an application package to those seeking to use paratransit services. After receiving a completed application package which includes the standard application, medical verification, and often the functional assessment, DART provides applicants with an eligibility determination within 21 days.

There are several types of eligibility that can be granted to an applicant. At the Regional Transportation Authority (RTA) serving suburban Chicago, applicants can be granted Unconditional, Conditional or Temporary eligibility after undergoing the application process which includes the medical verification and functional assessment as discussed above. Unconditional eligibility means that the patron is always unable to use the fixed route services because of a disability or health condition and is qualified for ADA paratransit on all trips. Conditional eligibility is granted when a passenger is able to utilize fixed-route services for some of the requested trips, but qualifies for ADA paratransit service when the disability or environmental barriers prevent the use of fixed-route transit service. Finally, Temporary eligibility is granted when a health condition or disability temporarily prevents a patron from utilizing fixed-route services. If a passenger is certified conditional, each trip requested will usually go through a trip screening process before identifying whether the trip is eligible under the paratransit program. This is easily done by verifying the pick-up and drop-off addresses of the requested trip. Trip verification will be further discussed in the following section.

Transit agencies can make non-ADA eligibility determinations as well. In these cases, the local transit agency has much greater leeway it setting criteria and standards. Examples would include limiting the eligibility to certain population groups (e.g., seniors 65 years old and older), travel areas, or by prioritizing trip types.

\section{$\underline{\text { Reservation / Scheduling / Dispatch Process }}$}

In reviewing past research and reports, and in evaluating the processes used by transit agencies in addressing the paratransit trip process, one issue clearly stood out. Agencies that have a well-coordinated reservation/scheduling/dispatch process and a good communications system are better able to control the ever increasing costs of providing paratransit services. Ideally, an agency that can establish a smooth call intake process, develop an attainable operational schedule, and implement a dispatch process where all operators have direct communication with the control center have a distinct advantage in dealing with issues such as 
cancellations and no-shows, which can cause disruption in a daily schedule and negatively impact the efficiency of the service and consequently the financial bottom line.

\section{Reservation Process}

Each agency must establish a reservation process and communicate that process to its patrons. Reservation windows often are created to ensure riders get to their destinations on time. When calling for a pick-up time, it is important for both the reservationist and the patron to discuss actual pick-up time versus appointment times. Most agencies now establish 30-minute or greater pick-up windows which gives the agency some degree of flexibility while still providing the passenger with reasonable expectations. Most important is for the patron to understand the actual policies regarding pick-up and drop-off windows. Many transit agencies have developed rider guides that go step-by-step through the process of reserving and using paratransit services.

Certain technologies can vastly improve the reservation process. Automated phone systems allow for reminder or verification calls to the patron on the day and/or the day prior to travel. Such practices have been shown to greatly cut down the number of no-shows many agencies report and enhance the daily operations of the paratransit system.

The May 2007 evaluation by the Western Transportation Institute from Montana State University of installation of scheduling software for MET Transit in Billings, Montana, documented that assuming the costs of the hardware and software were amortized over a five-year period and taking into account the annual maintenance fees, MET only needed to decrease mileage and/or hours by approximately three percent for the software installation to provide a positive cost savings to the organization.

In addition to a call in-take system for paratransit trip reservations, many agencies have subscription service trips that make up a portion of their trip requests. Subscription service trips are trips that a patron makes multiple times per month, or possibly multiple times per week, and are of a specific origin and destination that does not change. Most often these types of trips are for employment, medical, and/or educational purposes. Many transit operators address the individual requirements for subscription trips within their rider guides that outline the paratransit program. 


\section{Scheduling}

Scheduling the daily paratransit itineraries is a logistical challenge due to the need to accommodate new trip requests, as well the standing subscription orders at each transit agency. Agencies using an automated scheduling system will have each day's schedule developed via computer. However, the daily schedule must be reviewed by employees to verify the process. The automated system can produce a schedule based only on the parameters set by the transit operator, so the staff charged with scheduling and dispatch must have some ability to manage the automated system, as necessary. After the computer system or scheduling personnel develop the daily schedule, driver manifests are produced. For systems without mobile data terminals (MDTs), the manifests are printed. With MDTs the manifests are kept in an electronic form, with only the next or the next few trips displayed on the terminal. The manifest shows each individual vehicle operator their daily pick-up and drop-off schedule. Usually within the riders guide, an agency will define its policy on pick-up and drop-off windows, which give the transit operator a small amount of leeway in travel and scheduled pick-up time, usually about 15 to 30 minutes.

One of the more common causes for disruption of a paratransit schedule gets are due to late trip cancellations or no-shows by patrons. While some degree of late trip cancellations and noshows are understandable; high rates of occurrences result in marked decreases in productivity. Most transit agencies have developed operating practices and policies to address these passenger practices that adversely impact productivity. Examples of operating practices include set procedure for reporting and documenting incidents, such as immediate reports to the dispatchers and accurate record keeping on trip manifests. On the policy side, procedures to monitor and proactively respond to patrons who exhibit such travel patterns.

\section{Dispatching}

The transit agency's dispatch system is the central and controlling operation center for paratransit operations. Once a daily schedule has been produced and a driver has been provided a daily manifest, the dispatchers must be available to deal with any changes or disruptions that the paratransit system encounters. The function of dispatching to know where the vehicles and the operators are at all times, should it be necessary to re-route or change a run. It is critical that agencies must have a policy or process to ensure it can identify the location of its operators throughout their shift. Some agencies have systems where the vehicle operator will check in with the dispatcher at each pick-up and drop-off location. This provides an open line of communication and alerts the dispatch center to any abnormalities the operator is facing (running late, arrived too early, patron no-show), allowing the dispatcher to make schedule 
adjustments as necessary. In larger systems, this type of driver check-in may not be possible due to the number of vehicles operating at one time. Often, larger systems will use a system in which vehicle operators contact the dispatch center only in the event of a problem (running late, no-show), so that dispatchers can make the necessary adjustments to the schedule.

With advances in technology, many agencies use mobile data terminals (MDTs) and automated vehicle location equipment that allows the dispatchers to know the precise location of each of the vehicles at all times. This allows for tweaks in the schedule to occur in real time, and often before issues arise. If the dispatchers are aware that an operator is running late, they may be able to reassign trips to other drivers, so as not to cause the rest of the daily schedule to be adversely affected.

\section{$\underline{\text { Utilizing Fixed Route Service }}$}

One of the most cost-effective ways to manage paratransit costs is to transition paratransit passengers who are able to utilize the fixed-route system.

The financial impact of moving even a single person from paratransit service to the fixed route system can be dramatic as detailed in this example using Sarasota, Florida's SCAT bus system. As reported in the Florida Commission for the Transportation Disadvantaged Annual Operating Reports, SCAT's per paratransit passenger cost was $\$ 27.92$ in 2007 . The SCAT fixed route service currently charges $75 \$$ as its base fare, with the discounted fare of $35 \$$. Monthly, or 30day passes, are available for $\$ 40$ and $\$ 20$ respectively.

As detailed in Exhibit 1, moving a single passenger from paratransit to fixed route service will result in monthly savings of $\$ 183$ for the infrequent rider and over $\$ 1,000$ for the five day per week rider. Even assuming that the transit system pays for the monthly pass, the transit system would realize annual savings of $\$ 2,200$ to $\$ 12,922$ respectively.

Exhibit 1

Savings Realized by Moving from Paratransit to Fixed Route Service

\begin{tabular}{|c|c|c|c|c|}
\hline Travel Frequency & $\begin{array}{c}\text { Trips per } \\
\text { Month }\end{array}$ & $\begin{array}{c}\text { Cost per } \\
\text { Month }\end{array}$ & $\begin{array}{c}\text { Cost of Fixed Route } \\
\text { Monthly Pass }\end{array}$ & $\begin{array}{c}\text { Monthly } \\
\text { Savings }\end{array}$ \\
\hline 1 roundtrip per week & 8 & $\$ 223.36$ & $\$ 40$ & $\$ 183.36$ \\
\hline 3 roundtrips per week & 24 & $\$ 670.08$ & $\$ 40$ & $\$ 630.08$ \\
\hline 5 roundtrips per week & 40 & $\$ 1,116.80$ & $\$ 40$ & $\$ 1,076.80$ \\
\hline
\end{tabular}


A few of the methods for a successful transition from paratransit to fixed route transit service are discussed in this section.

Providing accessible information on the fixed-route system

Many transit agencies provide their system information in a web-based ADA compliant format. Once a web-based system is offered, there are supplemental systems that allow users to view the information in a manner that is suitable for them. Many agencies offer printed materials, in Braille for example, that are suitable for those with varying disabilities. In addition, trip planning software can aid those patrons who may need additional assistance in planning their trips. Many transit agencies provide personal one-on-one travel training to those who may need it, especially in the case of route and/or system changes.

\section{Bus stop accessibility}

For riders with special needs to feel comfortable and safe riding the fixed-route system, bus stops must be safe, secure, and accessible to those patrons. For wheelchair bound patrons, the availability of concrete pads and/or sidewalks to and from bus stops is vitally important. In addition, lighting and amenities such as benches and shelters can assist patrons with special needs. By working with patrons and understanding what their travel needs are (where they are going), transit agencies are better able to site these amenities where they are most needed.

The Maryland MTA, which had undertaken a program to improve some of its fixed-route stops, examined the average costs of bus stop improvements. What was designated as simple bus stop improvements typically included minor sidewalk improvements and the installation a post and sign and averaged $\$ 7,000$ per bus stop. Enhanced improvements which included lighted shelters, a bench, and trash cans in addition to the minor sidewalk improvements and the installation a post and sign averaged $\$ 58,000$ per bus stop. Maryland MTA, estimating that the fully loaded of their MTA paratransit trip as $\$ 76.64$ per trip, concluded that these capital costs would be recovered in ten weeks for the simple stop and eighteen weeks for the enhanced stop if one paratransit passenger who used the paratransit service five days per week (i.e., ten trips) would be able to switch to the fixed route services due to the bus stop improvement.

\section{Automated stop announcements}

According to ADA regulations, fixed-route operators are required to announce bus stops along the route. Regular announcements can provide sight impaired individuals' assistance in understanding the whereabouts of the vehicle along the fixed-route. As existing bus fleets are 
replaced within a transit agency, there are more opportunities to use advanced technologies. Many new buses are now equipped with automated systems that will continually make route announcements without the assistance of the operator. When a patron who is used to paratransit services can feel more assured that they will be able to navigate the fixed route bus system successfully, they will be more willing to make the transition from paratransit to fixedroute service.

\section{Vehicles}

Several features often standard on buses can aid in the transition of paratransit passengers to the fixed-route system. This also relates to the advancement of technologies that are being built into the new bus fleets available to transit agencies. Buses with kneeling features allow operators to lower the front entry door, reducing the distance a passenger must step up to enter the bus. It is imperative that operators be trained on its use and how to recognize patrons that require assistance. Along low floor buses allow patrons to board the vehicle utilizing a ramp, rather than a hydraulic wheelchair lift. In addition to providing ease of boarding for wheelchair and scooter passengers, it greatly helps passengers with baby strollers and those patrons who may have problems climbing the steps. Again, it is necessary for operators to have proper training in the use of the ramps and how they may assist passengers in need of additional support.

\section{$\underline{\text { Travel Training Programs }}$}

As previously discussed in the eligibility process section, travel training can be made available to those patrons who have the potential to use the fixed-route system if they receive additional guidance and training. Many public transit agencies use in-house and/or contracted trainers for patrons who can achieve event greater mobility options by learning to use the fixed route bus services.

The Regional Transportation Authority (RTA) serving suburban Chicago provides a staff of trainers to assist passengers. After the ADA eligibility and certification process is complete, RTA sets up a travel training assessment to see what type of training the patron would most benefit from. Training is usually a one-on-one experience, including an overview of policies and procedures, practicing boarding/alighting out-of-service buses and actual in-the-field travel with the trainer. Specific issues such as the use of fare cards, the bus lift processes, and wheelchair securement are addressed with the patron. Upon completion of the travel training, a determination regarding ADA paratransit eligibility is made based on the individual's abilities to use the fixed-route system. 
Travel training, while an upfront cost with each new paratransit patron, can save transit agencies considerable amounts of money. A report by Project Action outlining innovative practices in paratransit services found that several agencies have documented overall savings using a travel training program. In the report, Seattle Metro reported an annual expenditure of about $\$ 160,000$ for travel training, but estimated it saved over $\$ 400,000$ in paratransit costs by successfully transitioning paratransit patrons to the fixed-route system. Similarly, Broward County Transit in south Florida reported a savings of $\$ 2,300$ per year for each patron who was successfully trained to use the fixed-route system.

Several companies provide a contractual service for travel training. While some transit agencies have in-house training programs, many opt for the assistance these outside organizations provide. These organizations assist a transit agency with:

- Determining if training is a realistic option for the agency

- Training in-house staff to implementing a training program

- Assisting in the initiation of a travel training system

- Providing the training for transit agencies

The application of technology to assist travel training is being studied by Florida DOT sponsored research at the CUTR. Building upon research efforts on the potential use of smart phone applications to influence travel behavior, the application of cell phone technology equipped with global positioning device capability to assist and aid transit riders with special needs is now under study. This concept tracks the special needs passenger while riding the bus and alerts them when approaching their bus stops. This will hopefully lead to another tool to assist special need passengers successfully move to fixed route transit service.

\section{Coordination with other Transportation Providers}

Coordination among providers and agencies that offer transportation alternatives offers the potential to increase transportation availability and access to jobs, enhance service quality, eliminate duplicative services, and substantially improve cost effectiveness in the delivery of transportation to those most in need. While some states are just beginning, many others are continuing efforts to implement a coordinated system to provide transportation options. Successful coordination of services usually results in more effectiveness and efficiency. Often, this is measured by an increase in the number of trips offered for a lower cost per trip. 
There has been considerable discussion and research on the subject of the coordination of paratransit services, some originating in the 1970's. This brief discussion focuses on the most recent efforts in the transit industry.

At all levels of government (federal, state and local), creative ideas about how to best serve the transportation disadvantaged population have been crafted in programs and policies. In 2004, President George W. Bush issued an executive order on Human Service Transportation. The order was "to enhance access to transportation to improve mobility, employment opportunities, and access to community services for persons who are transportation disadvantaged," and it established the Interagency Transportation Coordinating Council on Access and Mobility (CCAM). The membership of the interagency council comprises the Secretaries of the Departments of Transportation, Health \& Human Services, Education, Labor, Veterans Affairs, Agriculture, Housing and Urban Development, and the Interior; in addition to the Attorney General and the Commissioner of Social Security.

Under its United We Ride program, CCAM has recognized several states for their commitment to provide specialized transportation services to those in need with leadership awards. Florida, Maryland, North Carolina, Ohio and Washington were recognized for outstanding work to develop coordinated systems and serve as models for other states.

CCAM continues its national action plan that seeks to develop outreach and education plans for coordinated human service transportation; simplify access to transportation services; reduce restrictive and duplicative laws, regulations and programs at the Federal level; standardize the cost allocation processes; and document successful strategies in the delivery of human service transportation at all levels of government.

On a more local and regional level, there are also many programs aimed at coordinated transportation. In San Diego, California, the Specialized Transportation Referral and Information for the Disabled and Elderly (STRIDE) program began in 2001. STRIDE is a web-based service that provides information on more than 190 specialized transportation programs available in the area. The mission of STRIDE is "to provide a referral service with comprehensive information of specialized transportation providers designed to improve access to transportation and to enhance the quality of life of seniors and persons with disabilities." In Licking County, Ohio, 
several social service agencies work together to provide transportation services for memberagency clients. Member agencies make every effort to use vehicles and drivers operated by other member agencies to transport clients in a more efficient and effective manner than could be achieved individually. A third party contractor also is available to provide trips that would otherwise go unmet by the current member agencies' transportation resources. A program known as People for People (PfP) was established in Yakima, Washington, and now has a Transportation Program that provides elderly and disabled transportation services, Medicaid transportation services, job access and reverse commute program transportation, and rural intercity bus service. Washington contracts with PfP using FTA Section 5311 rural transportation funding. In turn, PfP coordinates with several social service agencies in the local area to provide transportation to those residents who would have no other means of travel to work, school, medical appointments, and shopping.

In establishing or enhancing existing coordinated systems several key items seem to be common to successful systems. These items include a centralized reservation system, a common eligibility process, and the commitment to serve those residents who may not have another means of transportation available to them. 


\section{Chapter Three \\ Expense Categories and Trends}

One task of this research was to identify the major expense categories for paratransit services and factors impacting these cost centers. The objective was to determine the more significant expense categories and to document the changes in cost by categories over time. The two primary sources of financial data utilized in this effort were the National Transit Database (NTD) reports and the Florida Commission for the Transportation Disadvantaged Annual Operating Reports. Using these two data sources, the trends in the costs of providing paratransit services and the major expense categories and factors impacting these cost centers were identified and documented for Florida public paratransit systems. This chapter provides a review and summary of the relevant findings.

\section{Data Sources}

This research focused on the public paratransit systems operating in Florida, using two different data sources.

\section{National Transit Database}

The first data source focused on the paratransit services provided in part to satisfy the U.S. Department of Transportation Federal Transit Administration's (FTA) required Complementary ADA Paratransit services that must be provided by the public transit agencies receiving FTA Section 5307 funding.

As a requirement of receiving federal transit funds, public transit agencies are required to report a variety of data in a standardized format to the FTA, which results in what is known as the National Transit Database (NTD). These documents provide standardized measures of reporting that enable a more accurate comparison of information between properties. Since 1979, when this reporting requirement was instituted, additional refinements in data collection and reporting have increased the accuracy and comparability of the data.

For this analysis, the NTD ADA related expenses reported by the 25 Florida public transit agencies required to submit the NTD reports were examined for the six fiscal years from 
FY1999-2000 through FY 2004-2005. The Florida Transit Information System program (FTIS), which was jointly developed by FDOT and the Lehman Center for Transportation Research at Florida International University, was used to compile this data set.

\section{Annual Operating Reports}

Since, in many cases, NTD data for the urbanized transit systems receiving FTA transit funding may be limited to only their Complementary ADA Paratransit services, and expense data are presented with limited detail (i.e., operating and maintenance expenses), an alternative data source was also used in this research effort.

The mission of the Florida Commission for the Transportation Disadvantaged is to ensure the availability of efficient, cost-effective, and quality transportation services for transportation disadvantaged persons throughout Florida. This is accomplished through coordinating agreements for the provision of paratransit services for each of Florida's 67 counties. One of the requirements of the coordinating agreements is that each local Community Transportation Coordinator (CTC) must submit Annual Operating Reports (AOR) that provide a wide variety of operating and financial data based on the State fiscal year of July $1^{\text {st }}$ through June $30^{\text {th }}$. This report provides cumulative operational statistics and trends on each coordinated transportation system and provides performance measures for all the coordinated systems.

For this analysis, the AOR data from all 67 Florida counties for the State fiscal years from 20022003 though 2005-2006 was used to provide details on the 12 expense categories reported annually in the AOR.

\section{Expense Categories}

The AOR provides a much richer and detailed data base for this research effort. First, data are available from all 67 Florida counties. This provides a broader picture of paratransit costs since it includes both urban and rural operating environments. Another benefit that the AOR provides is a more detailed breakdown of expense components. Exhibit 2 provides the 12 major expense categories detailed in the AOR. 


\section{Exhibit 2 \\ Annual Operating Report Expense Categories}

\begin{tabular}{|c|c|}
\hline Expense Component & Description \\
\hline Labor (501) & $\begin{array}{l}\text { - Operator/Driver Salaries and Wages } \\
\text { - Training Salaries and Wages } \\
\text { - Dispatcher Salaries and Wages } \\
\text { - Administrative Salaries and Wages } \\
\text { - Management Salaries and Wages } \\
\text { - Scheduler Salaries/Customer Service Salaries and Wages } \\
\text { - Vehicle Maintenance Salaries and Wages } \\
\text { - Other Salaries and Wages }\end{array}$ \\
\hline Fringe Benefits (502) & $\begin{array}{l}\text { - Operators } \\
\text { - Training } \\
\text { - Dispatcher } \\
\text { - Administrative } \\
\text { - Management } \\
\text { - Scheduler } \\
\text { - Call Intake and Customer Service } \\
\text { - Vehicle Maintenance } \\
\text { - Other }\end{array}$ \\
\hline Services (503) & $\begin{array}{l}\text { - Management Service Fees } \\
\text { - Advertising Services Fees } \\
\text { - Professional and Technical } \\
\text { - Other Services } \\
\end{array}$ \\
\hline $\begin{array}{l}\text { Materials and Supplies } \\
\text { Consumed (504) }\end{array}$ & $\begin{array}{l}\text { - Fuel and Lubricants } \\
\text { - Tires and Tubes Consumed } \\
\text { - Inventory Purchases } \\
\text { - Other Materials and Supplies Consumed }\end{array}$ \\
\hline Utilities (505) & $\begin{array}{l}\text { - Telephone } \\
\text { - Others }\end{array}$ \\
\hline Casualty and Liability (506) & $\begin{array}{l}\text { - Property Tax } \\
\text { - Vehicle Licensing and Registration Fees } \\
\text { - Other Taxes }\end{array}$ \\
\hline Taxes (507) & $\begin{array}{l}\text { - Property Tax } \\
\text { - Vehicle Licensing and Registration Fees } \\
\text { - Other Taxes }\end{array}$ \\
\hline $\begin{array}{l}\text { Purchased Transportation } \\
\text { Services (508) }\end{array}$ & $\begin{array}{l}\text { - Purchased Bus Pass Expenses } \\
\text { - School Bus Expenses } \\
\text { - Other }\end{array}$ \\
\hline Miscellaneous/Other (509) & $\begin{array}{l}\text { - Dues and Subscriptions } \\
\text { - Travel and Meetings } \\
\text { - Advertising/Promotion Media } \\
\text { - Uncollected Medicaid Co-payments } \\
\text { - Other }\end{array}$ \\
\hline Leases and Rentals (512) & $\begin{array}{l}\text { - Passenger Revenue Vehicles } \\
\text { - Service Vehicles } \\
\text { - Office Equipment } \\
\text { - Other }\end{array}$ \\
\hline Annual Depreciation (513) & $\begin{array}{l}\text { - Passenger Revenue Vehicles } \\
\text { - Service Vehicle Storage and Dispatch Center } \\
\text { - Maintenance Equipment and Data Processing Equipment } \\
\text { - Other }\end{array}$ \\
\hline Contributed Services (530) & $\begin{array}{l}\text { - The Value of Services Provided at No Cost to the Community } \\
\text { Transportation Coordinator Where the Value of the Service Can be } \\
\text { Claimed as an Allowable Source of Revenue. }\end{array}$ \\
\hline
\end{tabular}




\section{Observations}

\section{NTD Reports}

The NTD reports for the 25 Florida public transit agencies from the six fiscal years from FY1999-2000 through FY 2004-2005 permitted the tracking of the fixed route paratransit expenses over a six year period, as detailed in Exhibit 3. This graph plots both the total operating and total maintenance expenses of these 25 agencies. It should be noted that the operating expenses represent approximately 88 percent of the total annual paratransit expenses for this group of Florida transit systems. This indicates that cost management strategies directed toward managing trip demand and increasing system productivity would have significant benefits.

\section{Exhibit 3}

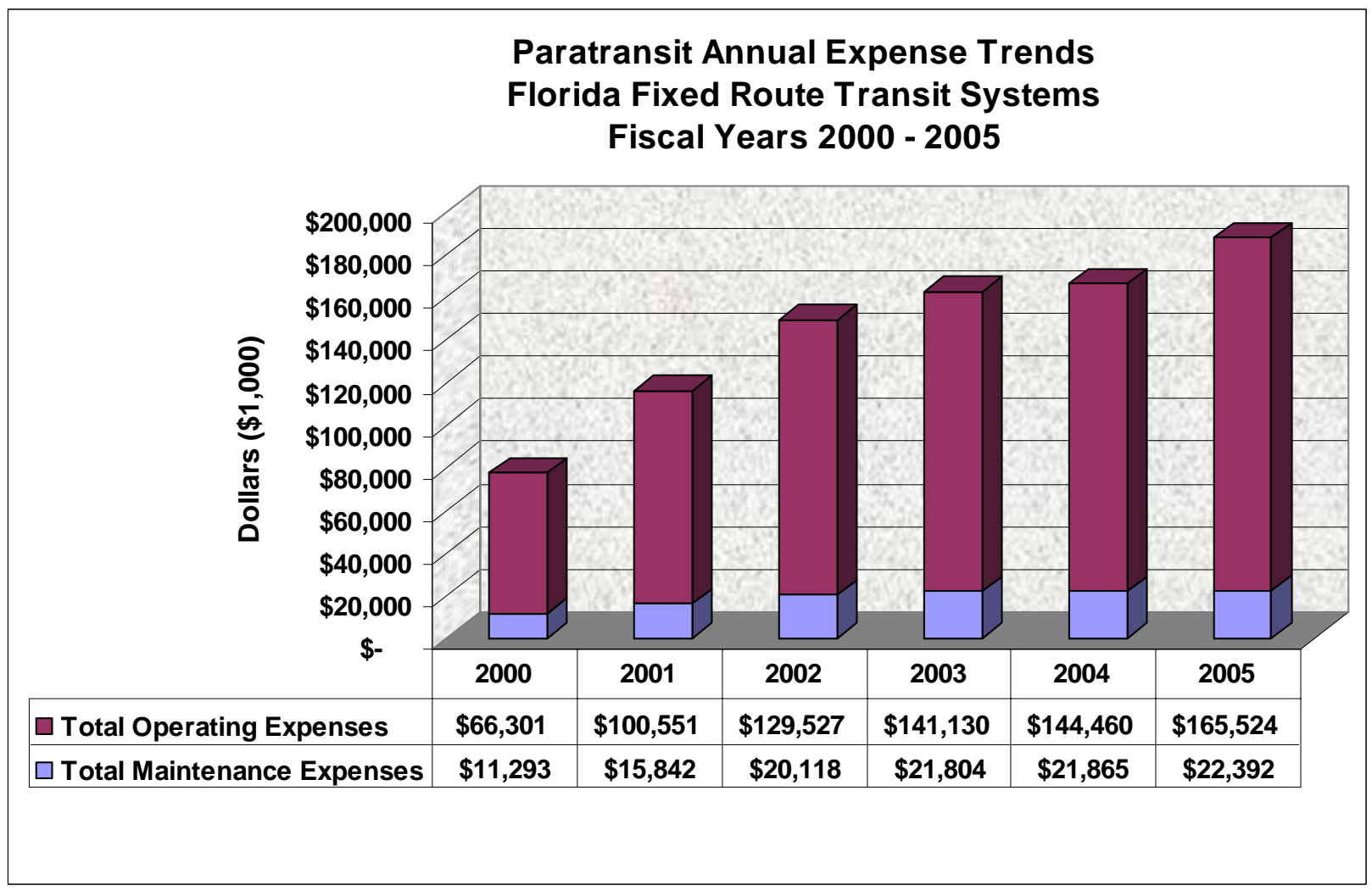


Examination of Exhibit 4, which provides the annual increases in expenses over this six year period, reveals that:

- the most significant annual increases occurred from FY 2000 to FY 2002

- paratransit maintenance expenses increased over $98 \%$ during the six year period - an average of close to $20 \%$ annually

- $\quad$ paratransit operating expenses increased at an even higher rate (i.e., close to $150 \%$ ) an average of $30 \%$ annually

- total paratransit expenses increased over $142 \%$ over the six year period - an average of over $28 \%$ annually

Exhibit 4

Six Year Trend in Annual Changes in Paratransit Expenses Florida Fixed Route Transit Systems

\begin{tabular}{|c|c|c|c|}
\hline Fiscal Year & $\begin{array}{c}\text { Maintenance Expense } \\
\text { Annual Increase }\end{array}$ & $\begin{array}{c}\text { Operating Expense } \\
\text { Annual Increase }\end{array}$ & $\begin{array}{c}\text { Total Expense Annual } \\
\text { Increases }\end{array}$ \\
\hline FY 2001 & $40.3 \%$ & $51.7 \%$ & $50.0 \%$ \\
\hline FY 2002 & $27.0 \%$ & $28.8 \%$ & $28.6 \%$ \\
\hline FY 2003 & $8.4 \%$ & $9.0 \%$ & $8.9 \%$ \\
\hline FY 2004 & $0.3 \%$ & $2.4 \%$ & $2.1 \%$ \\
\hline FY 2005 & $2.4 \%$ & $14.6 \%$ & $13.0 \%$ \\
\hline Five Year Change & $\mathbf{9 8 . 3 \%}$ & $\mathbf{1 4 9 . 7 \%}$ & $\mathbf{1 4 2 . 2 \%}$ \\
\hline
\end{tabular}

Exhibit 5 utilizes this same data set to calculate and plot the paratransit hourly expenses for these six years. For the 25 Florida transit systems, the cost per hour increased by 57 percent over this time frame - rising from $\$ 23.31$ to $\$ 36.52$ per hour. 


\section{Exhibit 5}

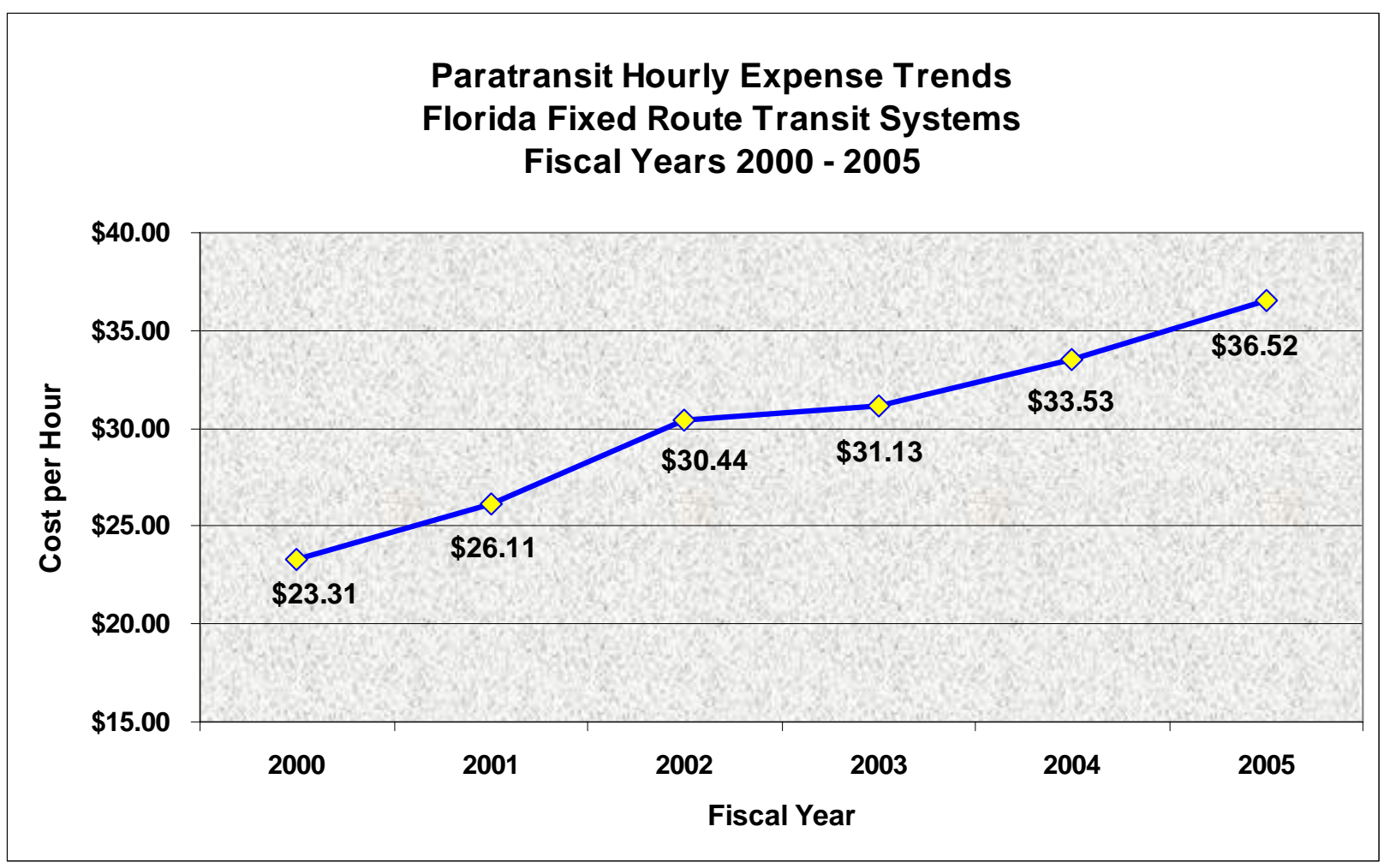

\section{Annual Operating Reports}

AOR data from the Florida Commission for the Transportation Disadvantaged for the State fiscal years from 2002-2003 though 2005-2006 was used to provide details on the 12 expense categories reported annually in the AOR. As mentioned previously, the AOR provides a much richer and detailed data base for this research effort. Data are available from all 67 Florida counties. The data includes both urban and rural operating environments. The AOR provide a more detailed breakdown of expense components. 
Exhibit 6 graphs the state totals of the transportation system's expenses for the four fiscal years from FY 2002-2003 through FY 2005-2006 by the 12 major expense components. Due to budgetary constraints the total expenses remained relatively stable over these four years but the increases in overall labor expenses (i.e., labor and purchased transportation) is apparent.

It should be noted that lowest three categories in cost impact (as detailed in Exhibit 6) only account for approximately 3 percent of the total expenses and are poorly detailed in Exhibit 5. These minimal cost components include utilities, contributed expenses, and taxes.

\section{Exhibit 6}

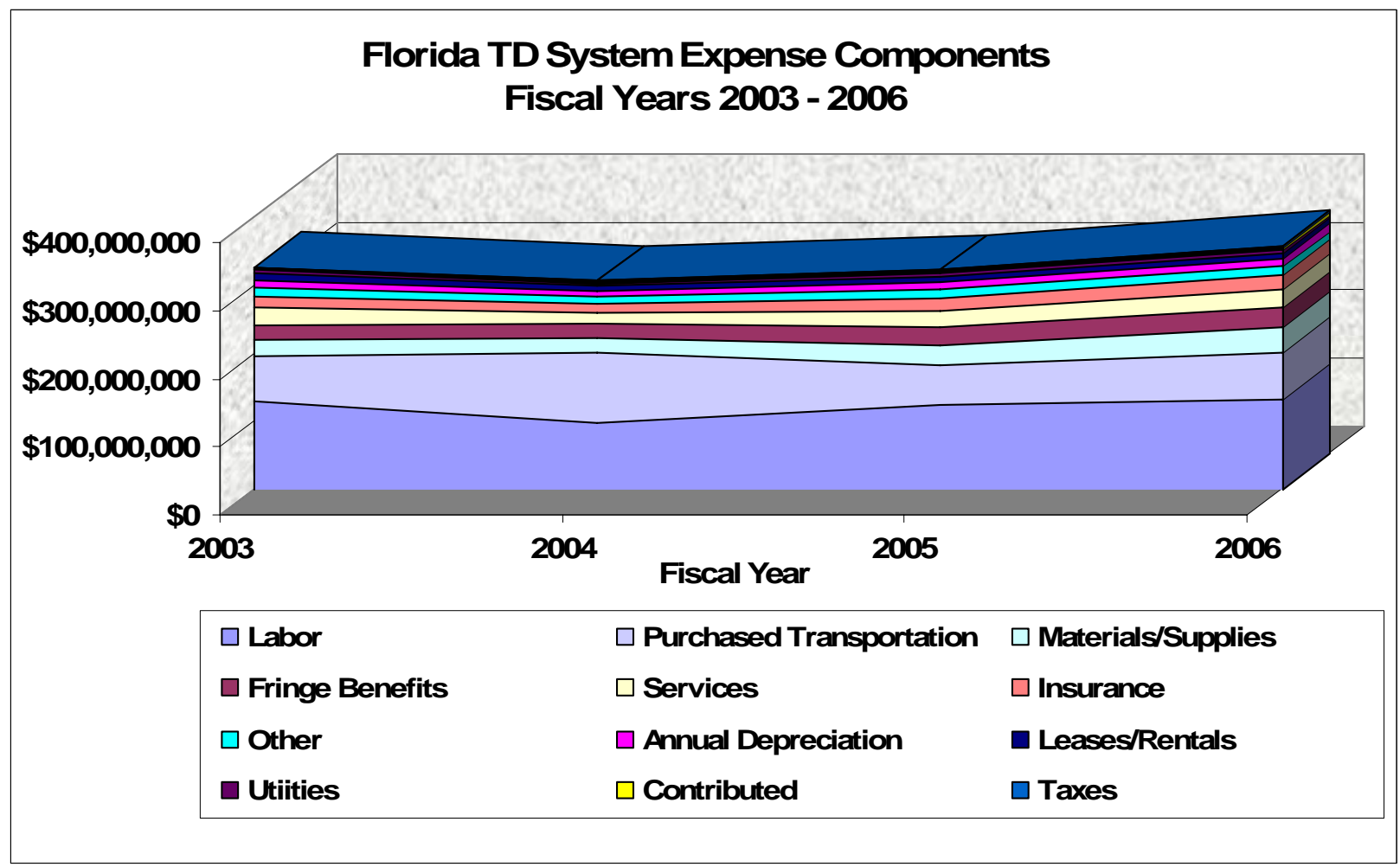


Exhibit 7 provides a more detailed look at the 12 major cost components included in the AOR submissions. Three of the most significant expense components related directly to the labor costs of providing services - labor, fringes, purchased transportation and services. Another significant cost component was materials and supplies, which includes fuel and vehicle parts for the non-purchased transportation cost components. Together, these four components account for 75 percent of all expenses.

\section{Exhibit 7}

\section{Florida TD System Average Expense Components Fiscal Year 2003 - 2006}

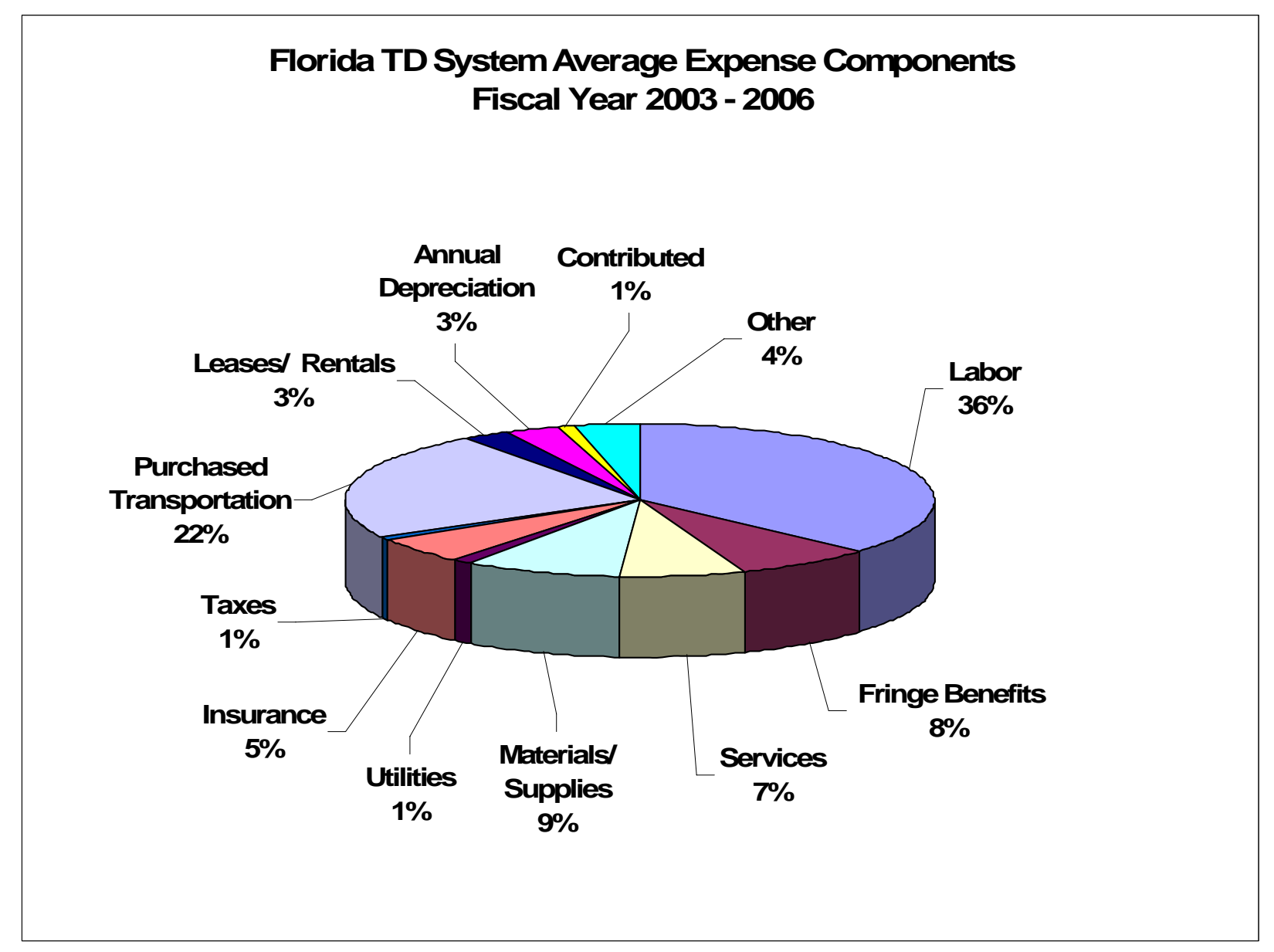




\section{Chapter Four \\ Examination of Existing Practices}

Another element of the research was to identify existing practices of Florida's transit systems and to identify efforts directed toward managing and containing paratransit costs. This effort used a survey instrument that was distributed to the Florida fixed route transit systems operating complementary ADA paratransit services. This chapter provides a review and summary of the relevant findings.

The survey was not designed to focus on hard fiscal information or directly on cost controlling practices, but rather attempted to ascertain existing operating and management approaches to the provision of paratransit services. This approach was deliberate and followed since transit agencies do not always associate the impact of their day to day decisions and operating practices on paratransit costs. The questions were developed to determine current practices in the eight categories, all of which have direct implications on the agency's cost of providing paratransit services.

\section{Survey Process}

\section{Survey Instrument}

A survey instrument containing 24 questions was developed around the following 8 cost management and containment categories:

- Certification Process

- Service Area Definitions

- Trip Prioritization and Management

- No-Show and Late Cancellation Practices

- Use of Technology

- Travel Training and Use of Fixed Route System

- Volunteer Programs

- Other Ideas and Practices 


\section{Survey Respondents}

In November 2007, surveys were distributed to the 22 Florida fixed-route systems that must provide ADA complementary paratransit service. As detailed in Exhibit 8, responses were received from 16 transit systems, representing a 73 percent response rate. A copy of the survey instrument is included as Appendix A.

\section{Exhibit 8}

\begin{tabular}{|l|l|}
\hline \multicolumn{2}{|c|}{ Florida Fixed Route Transit Systems Responding To Survey } \\
\hline Broward County Transit & Palm Tran \\
Collier County Area Transit & Pasco County Transit \\
JTA - Jacksonville & PSTA - Pinellas Suncoast \\
Lakeland/Citrus Connection & RTS - Gainesville \\
Lee County Transit & SCAT - Sarasota \\
LYNX - Orlando & StarMetro - Tallahassee \\
Miami-Dade Transit & St. Lucie County \\
Manatee County Area Transit & VOTRAN - Volusia County \\
\hline
\end{tabular}

\section{Survey Findings}

The following sections provide a summary of the significant responses organized around the surveys eight cost management and containment categories.

\section{Certification Process}

The determination of who is eligible for ADA complementary and other paratransit services is a critical step in the management of the costs of providing paratransit services. While transit agencies must adhere to both ADA and U.S. Department of Transportation regulations, without a well-defined eligibility determination process, an agency may inadvertently provide the complementary ADA paratransit trips to individuals who do not need paratransit services. NonADA paratransit service, if justified, provides the service provider more options and greater flexibility in such areas as fares, trip priority, and trip limitations. Additionally, an inadequate certification process will not identify individuals who may be able to use fixed route service with other support such as travel training. 
Most ADA eligibility certification processes start with a written application that the applicant must complete and submit. Most application processes consist of two components. The first is the standard application portion in which the applicant provides general information, details of the disability or condition that makes it difficult or impossible to ride the fixed route transit service, and a series of questions used to assess their circumstances. The second standard component is the medical verification, which asks a medical professional to review the applicant's information for accuracy and provide an assessment of the applicant's need for the specialized paratransit services. Many transit agencies have added a functional assessment process that requires the applicant to be interviewed in person and to undergo a variety of physical and mental functional assessments. When required, most transit agencies provide transportation to and from the assessment facility.

Initially, many transit agencies had simple application forms and did not require extensive medical verification, and few conducted any type of functional assessments. With the passage of time and as the costs and demands for complementary ADA paratransit services continued to increase, transit agencies have focused more attention on the certification process. The next three exhibits report on the survey questions focusing on three specific issues related to practices in the agency certification process.

\section{Exhibit 9}

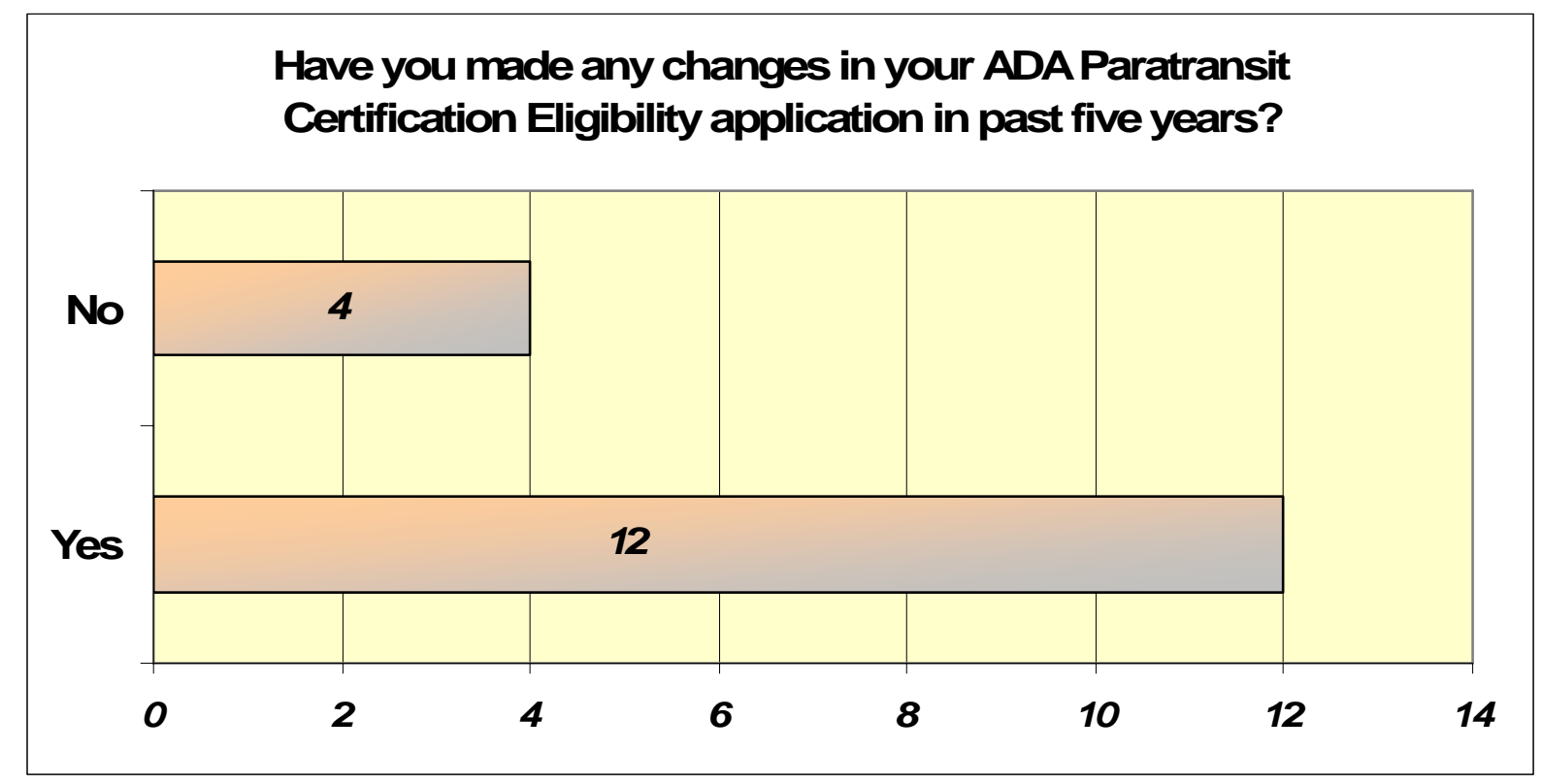


As detailed in Exhibit 9, 75 percent of responding Florida transit agencies made changes in their complementary ADA paratransit application between 2002 and 2007. This is an indication that the majority of transit agencies are taking proactive steps to manage the expenses of their paratransit services by using the certification process as a means to identify those applicants that could utilize the fixed route transit services and, thus, reducing the number of applicants deemed eligible for paratransit services.

Examples of changes made to the certification application form include:

- The addition of a medical professional's verification of the applicants disabilities

- To make the application more user friendly and understandable

- To improve the clarity and comprehensiveness of the questions

- To accommodate the move toward in-person assessments as to the applicants ability to utilize the fixed route transit services

- As a result in improvements to the fixed route transit system's accessibility

- To offer travel training opportunities to the applicant 
Exhibit 10

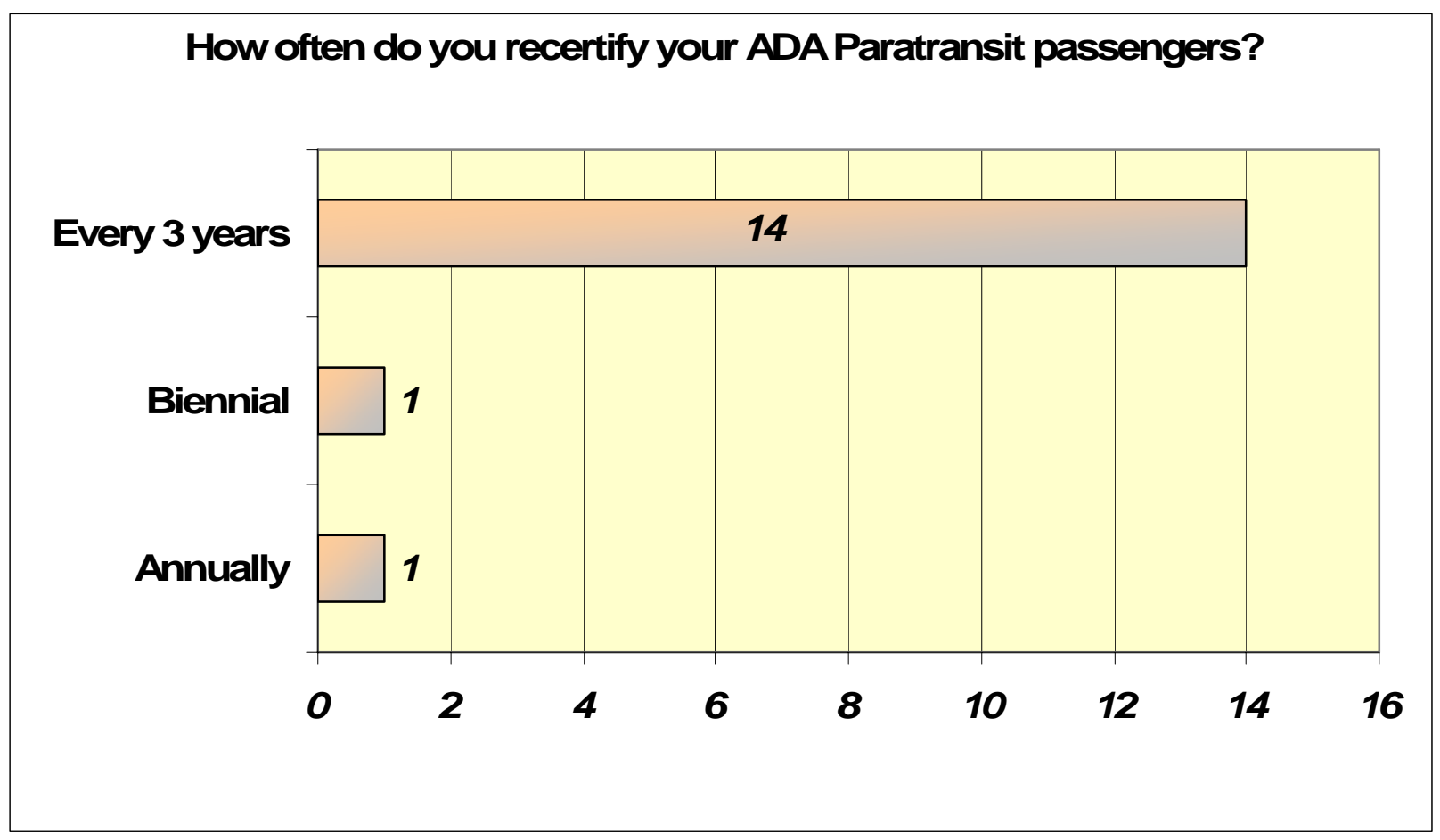

Another management technique is to keep an up-to-date and accurate register of eligible passengers. One of the essential steps to accomplish this is to conduct recertifications of existing passengers. This process also allows the agency to update and fine-tune its application process. Additionally, the recertification process permits the agency to eliminate passengers who are deceased or those who have relocated another community from their rosters. Since this process requires a significant expenditure of time and effort by both the agency and the passengers, this question was posed to determine the current practice of responding Florida agencies. As detailed in Exhibit 10, the vast majority of the transit agencies have settled upon every three years as the optimal cycle for recertification. 
Exhibit 11

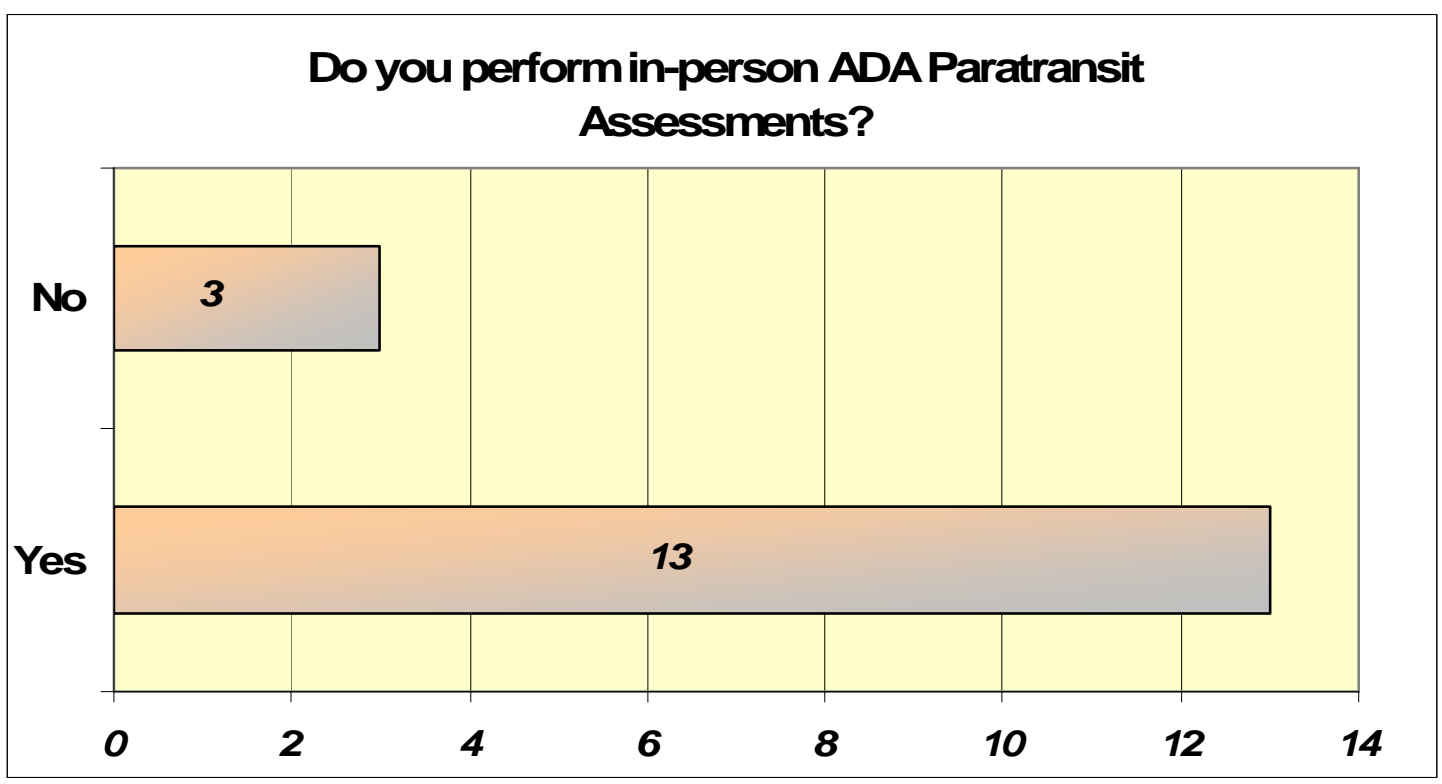

As detailed previously, the trend had been to conduct some in-person functional assessments as part of the eligibility process. The local policy decision is to determine what level of functional assessments can be justified economically to identify those applicants who are able to utilize the normal, fixed route transit service.

Exhibit 11 shows that 81 percent of the responding Florida systems conduct such assessments for some of their applicants. While many systems conducted functional assessments on 100 percent of their applicants, many chose not to assess those applicants who were most likely eligible based upon their applications and physicians assessments. Some other common categories of exception utilized by many transit agencies include the legally blind, skilled nursing home residents, and the very senior (i.e., age 80+) applicants. The reasoning for exempting these applicant groups is that since most are deemed eligible, the transit agencies can avoid the expenses associated with in-person assessments. 


\section{$\underline{\text { Trip Management }}$}

Another area that has promise for the management of paratransit costs relates to policies and practices in the scheduling of paratransit trips. A variety of practices were identified that allow some control to be imposed on this aspect of the service delivery.

Exhibits 12 through 17 summarize the responses to six questions related to trip management. Among the management practices explored include:

- Same day scheduling of trips

- $\quad$ Setting of system's pick-up window

- Using reminder and appointment verification calls

- Setting of system's service delivery parameters

- Permitting negotiation of travel times in reservation process

- Utilizing subcontractors to provide service

\section{Exhibit 12}

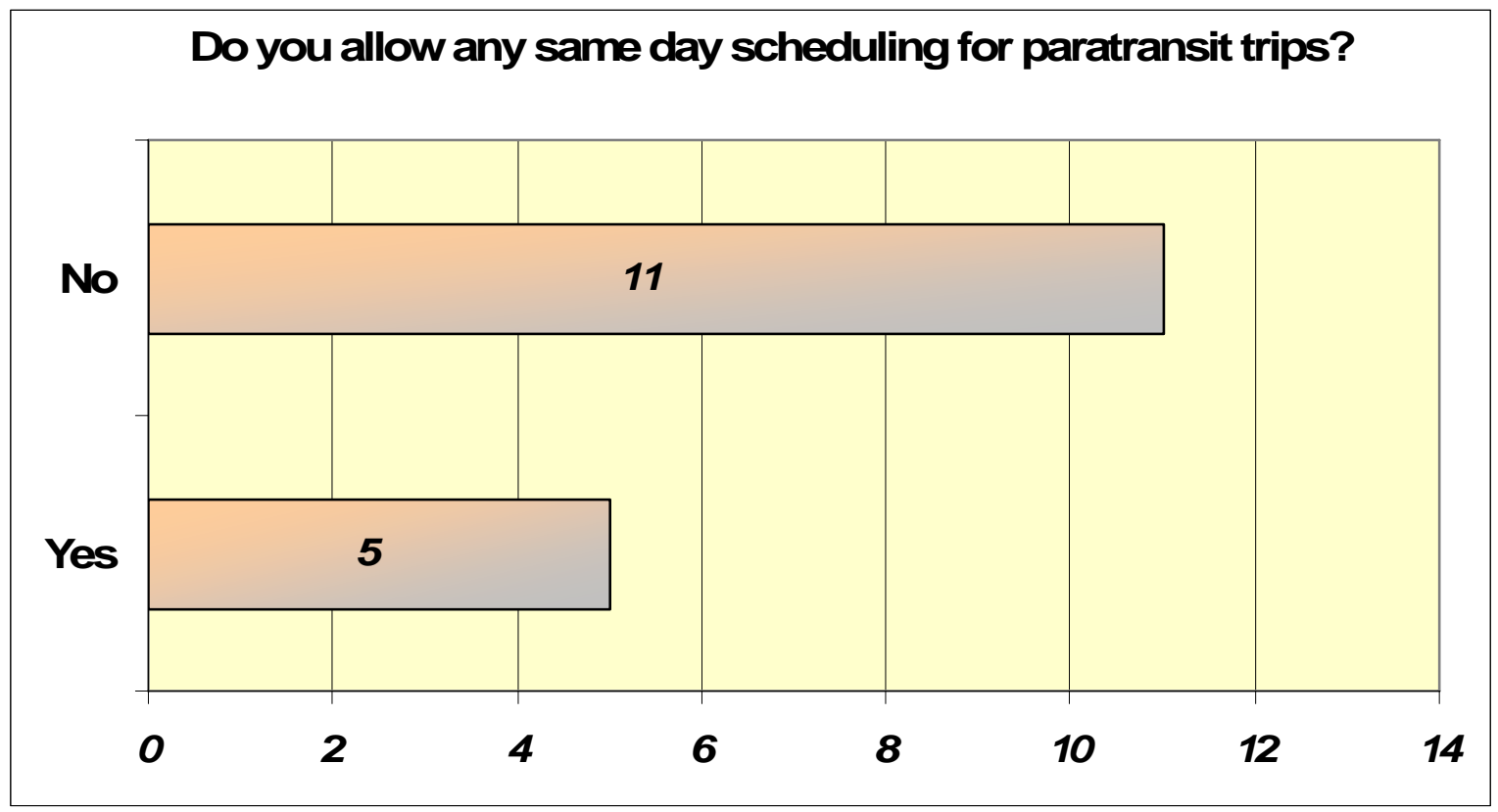

One of the emerging practices is for paratransit systems to permit same-day scheduling for paratransit trips, rather than require 24-hour or prior-day reservations. By using newer scheduling and trip management technologies, systems can now accept same-day reservations 
to help fill unproductive time created by no-shows and cancellations. As detailed in Exhibit 12, only 31 percent of the responding Florida systems currently allow same-day reservations.

The benefits of same day scheduling is that it permits the transit agencies to utilize the dead (i.e., unproductive) time in individual driver trip manifests that are created by no-shows and late cancellations, thereby improving the system performance measures and productivity. Additionally, it offers the passengers a higher level of service, as well as reducing the backlog of travel demand.

\section{Exhibit 13}

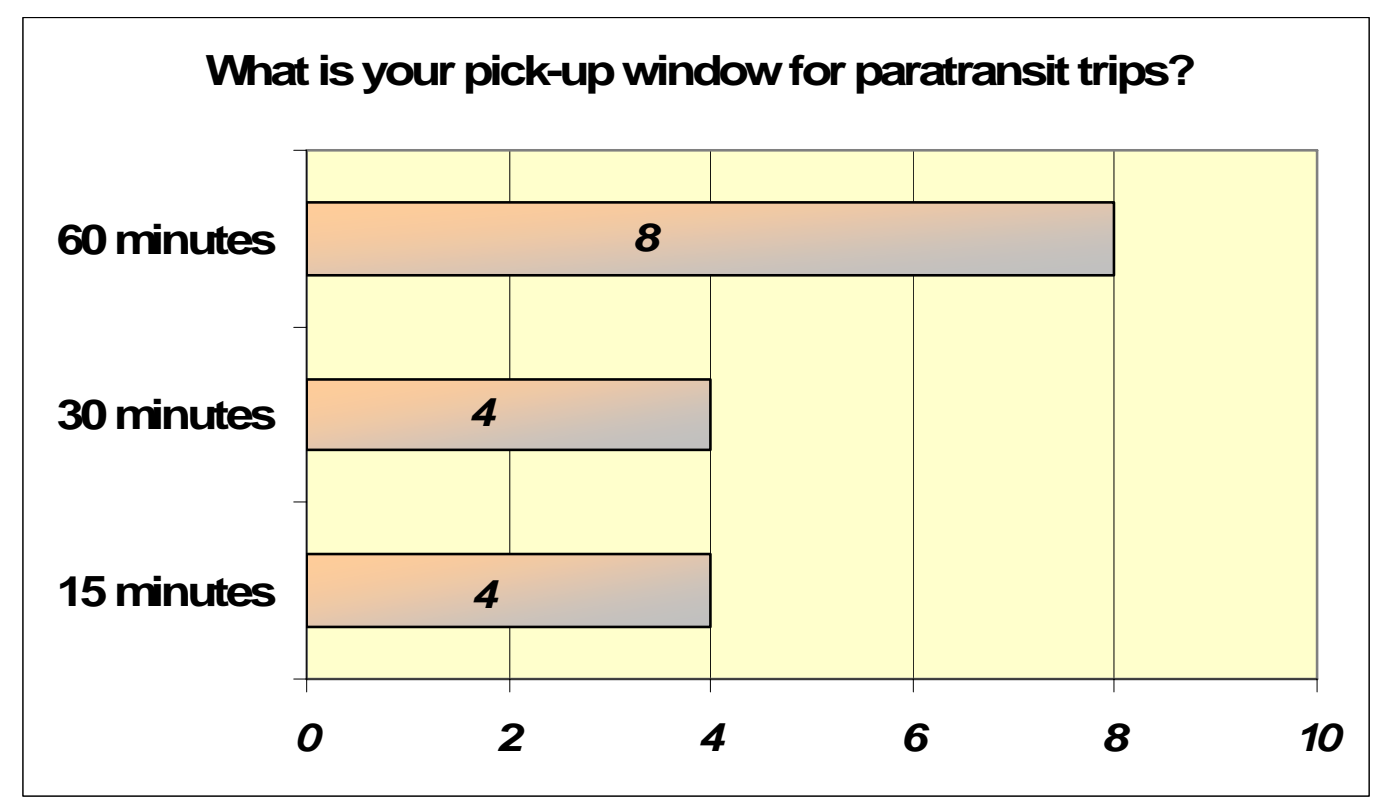

Establishing the system's practice for pick-up window policy is a critical step in determining how the paratransit trips are scheduled and provided. The pick-up window is the window of time before and after the scheduled pick-up time that the passenger must be ready and waiting for the paratransit vehicle to arrive. It was discovered that each system defines the pick-up window in different ways. For some it was the time before the scheduled pick-up time that the passenger had to be ready. For others, it was defined as the time to be ready before or after the pick-up time.

Pick-up windows present a dilemma for those systems focusing primarily on cost control. The shorter pick-up window will require the need for additional resources (i.e., operators and vehicles) and a more sophisticated scheduling/dispatch system. When properly managed, the 
additional costs may be accommodated by more efficiently scheduled service and not adversely impact costs. The quality of service provided to the patrons is greatly approved and possibly could reduce the number of no-show incidents.

Exhibit 13 indicates that the Florida systems' pick-up windows range from as low as 15 minutes to as high as one hour. The larger the pick-up window, the more flexibility is provided in scheduling paratransit trips - a benefit to the service provider. However, the larger pick-up windows result in a lower quality of service to the passengers.

\section{Exhibit 14}

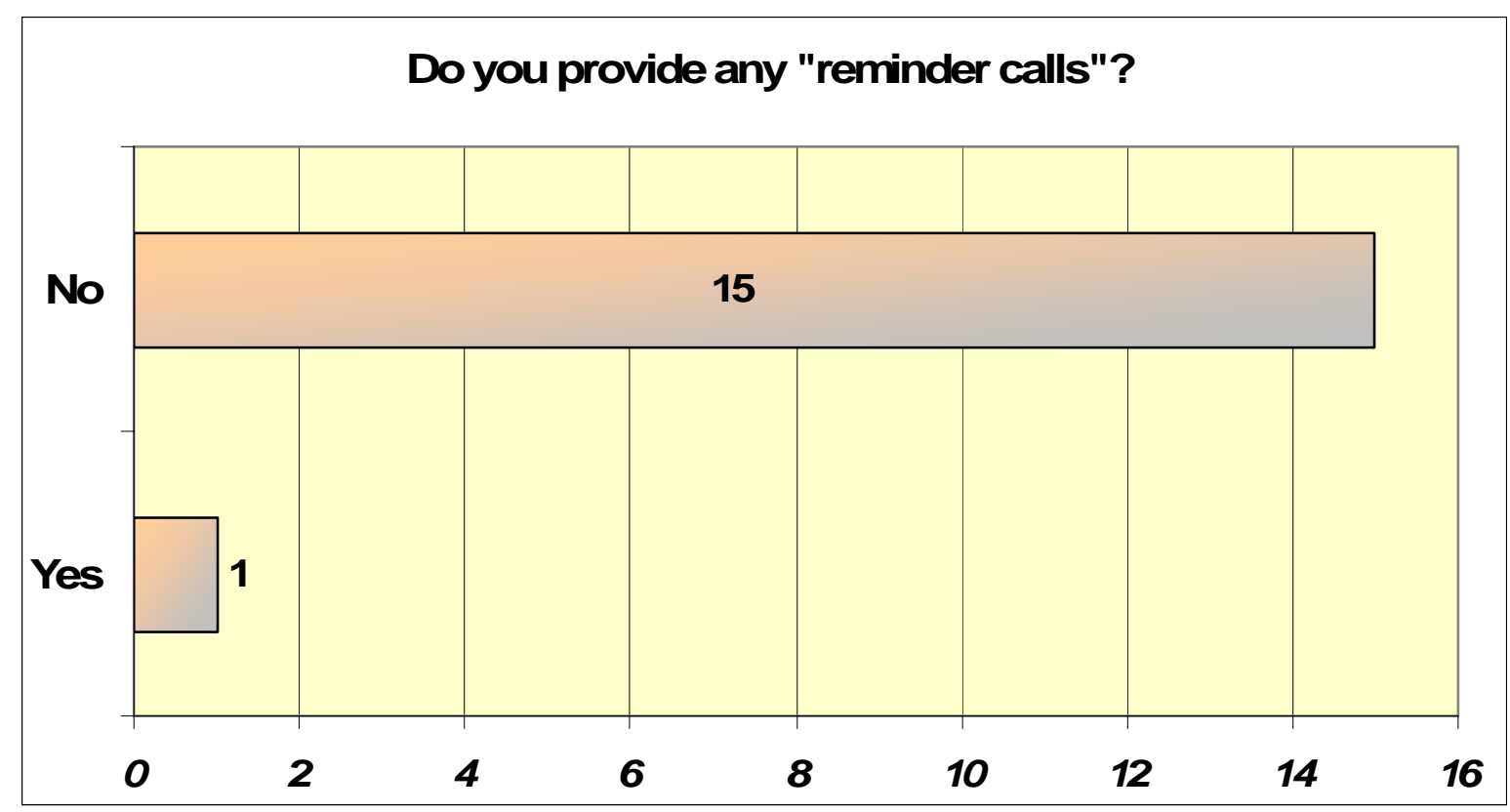

The successful coordination between the arrival of the paratransit vehicle and preparedness of the passenger is a critical factor for efficient operations. Effective education of the paratransit passengers as to their responsibilities will pay off in dividends to the system. The bane of effective operations is when the vehicle arrives as scheduled, but no passenger can be found. After several minutes of delay, the vehicle must then move on without the passenger. The result is unproductive time, wasted miles, a decrease in productivity, and in most cases a loss of revenue. 
Nationally some transit agencies routinely telephone scheduled passenger the day before their trip to both make certain that the trip is still required and to confirms the trip schedule specifics (i.e., pick-up time, pick-up location, and destination). This permits an opportunity to adjust the driver's trip manifest in the event the trip is no longer needed or the trip details need amended.

Similarly, some systems either call or have the drivers call the passenger shortly before their scheduled pick-up time with an estimated time of arrival. This again reconfirms the trip is still needed and permits the passenger to be prepared and ready to board the paratransit vehicle upon its arrival - resulting in improved productivity as well as a higher quality of service delivery.

Unless the service provider has an automated telephone calling system, reminder calls must be done by a staff person, taking time and diverting the employee from other functions.

In addition to implementing solid no-show and late cancellation policies, which were addressed in another survey question, some systems are now making reminder telephone calls to some or all of their paratransit passengers reminding them of their travel reservation and confirming the details. Due to the time-intensiveness of this practice, most systems (94\%) do not currently do this in Florida, as detailed in Exhibit 14.

As additional technology is incorporated by the paratransit providers, additional utilization of automated customer call systems is anticipated. 


\section{Exhibit 15}

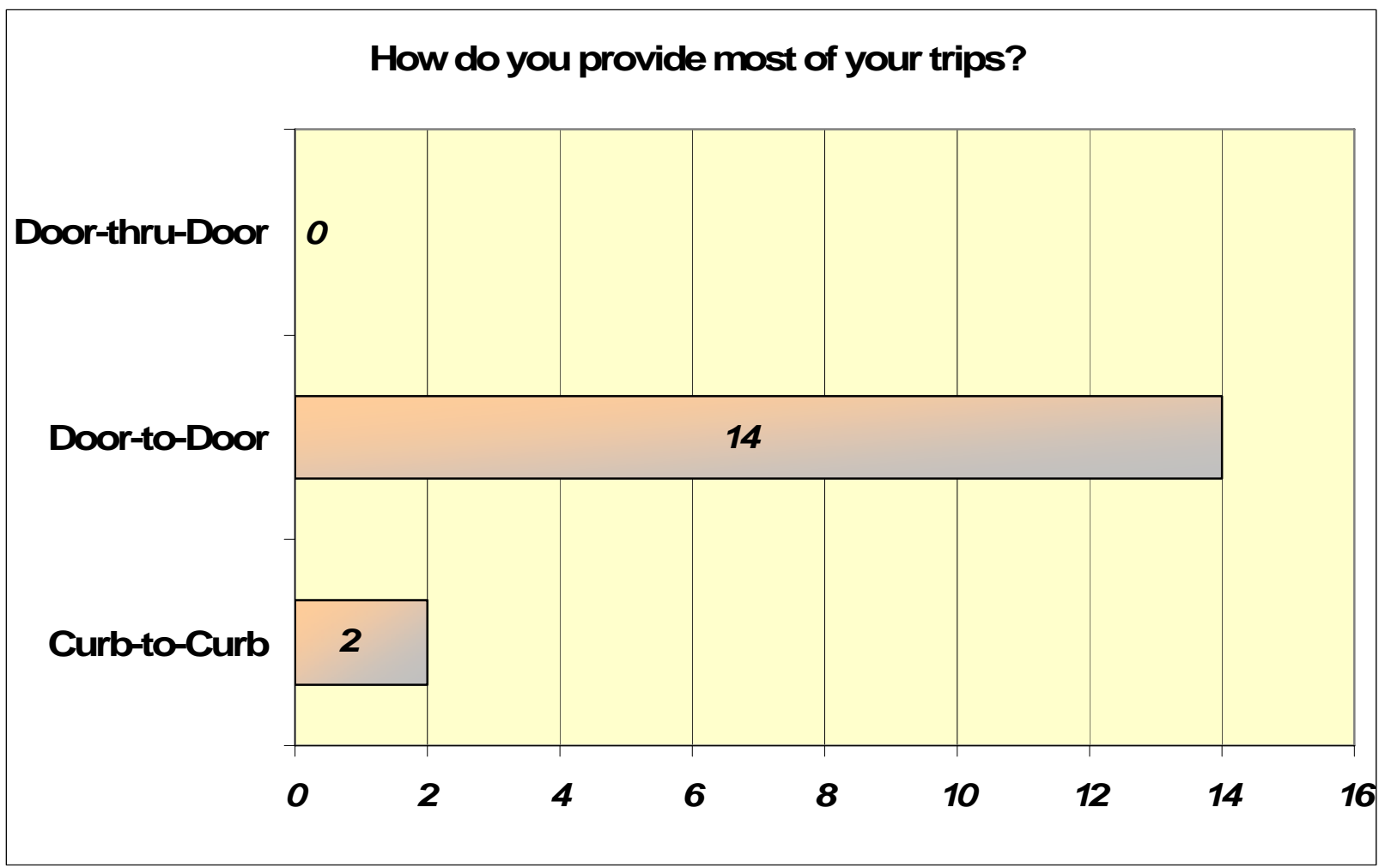

Another operational policy that impacts the productivity of paratransit operations is the system's policy on the amount of assistance the paratransit vehicle operator is expected to provide to the passengers. The most efficient service delivery from the operator's perspective is the curb-tocurb practice in which the passenger is expected to be waiting at the curb to be picked up and will be left at the curb on the return trip. No assistance is provided to the passenger to and from their trip origin or destination. When dealing with passengers with special needs, curb-to-curb service may not be practical due to physical limitation and the lack of adequate passenger shelter. Additionally, with large pick-up windows, the paratransit passenger would be required to be waiting at the curb for well over an hour or more.

As detailed in Exhibit 15, only 13 percent of the responding Florida systems use the curb-tocurb practice. The vast majority (88\%) use the door-to-door practice in which the vehicle operator is permitted to assist the passenger to and from the door of their origin or destination. 
Due to a variety of factors, including the need for additional dwell time and the liabilities to the drivers and the other passenger remaining on the vehicle, no Florida systems reported offering service door-thru-door, where the operator enters the passenger's residence and assists him/her in getting ready and boarding the bus. Where such higher levels of passenger assistance are required, systems require a travel companion be provided.

\section{Exhibit 16}

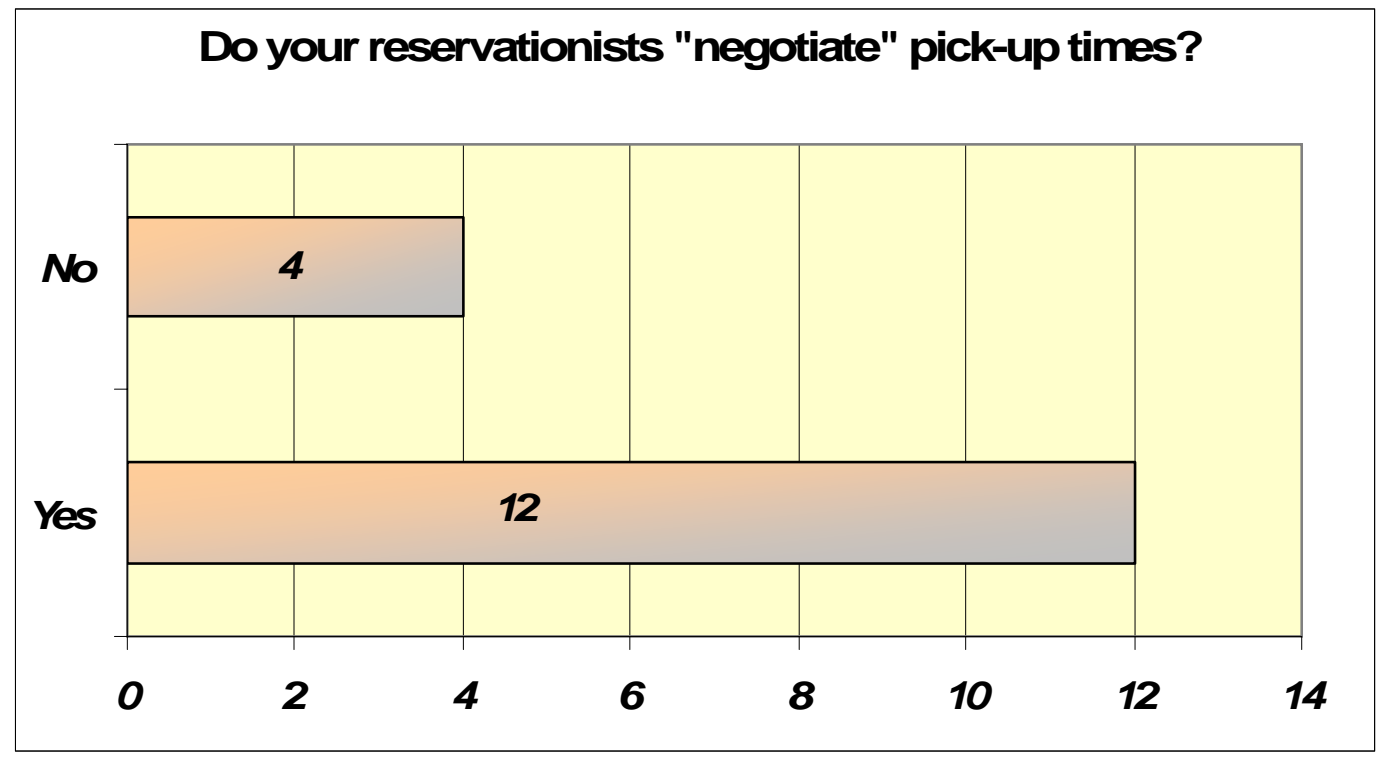

Another practice of the paratransit industry is to permit their reservationists to negotiate pick-up times with the passengers during the trip reservation process. By shifting the desired trip earlier or later, better utilization of the paratransit system resources are realized and overall more paratransit trips can be scheduled with the same amount of resources. This is ideal for those trips that are not as time-sensitive as medical appointments for example.

Exhibit 16 reveals that 75 percent of the Florida systems permit their reservationists to negotiate some of the trip request reservations. 


\section{Exhibit 17}

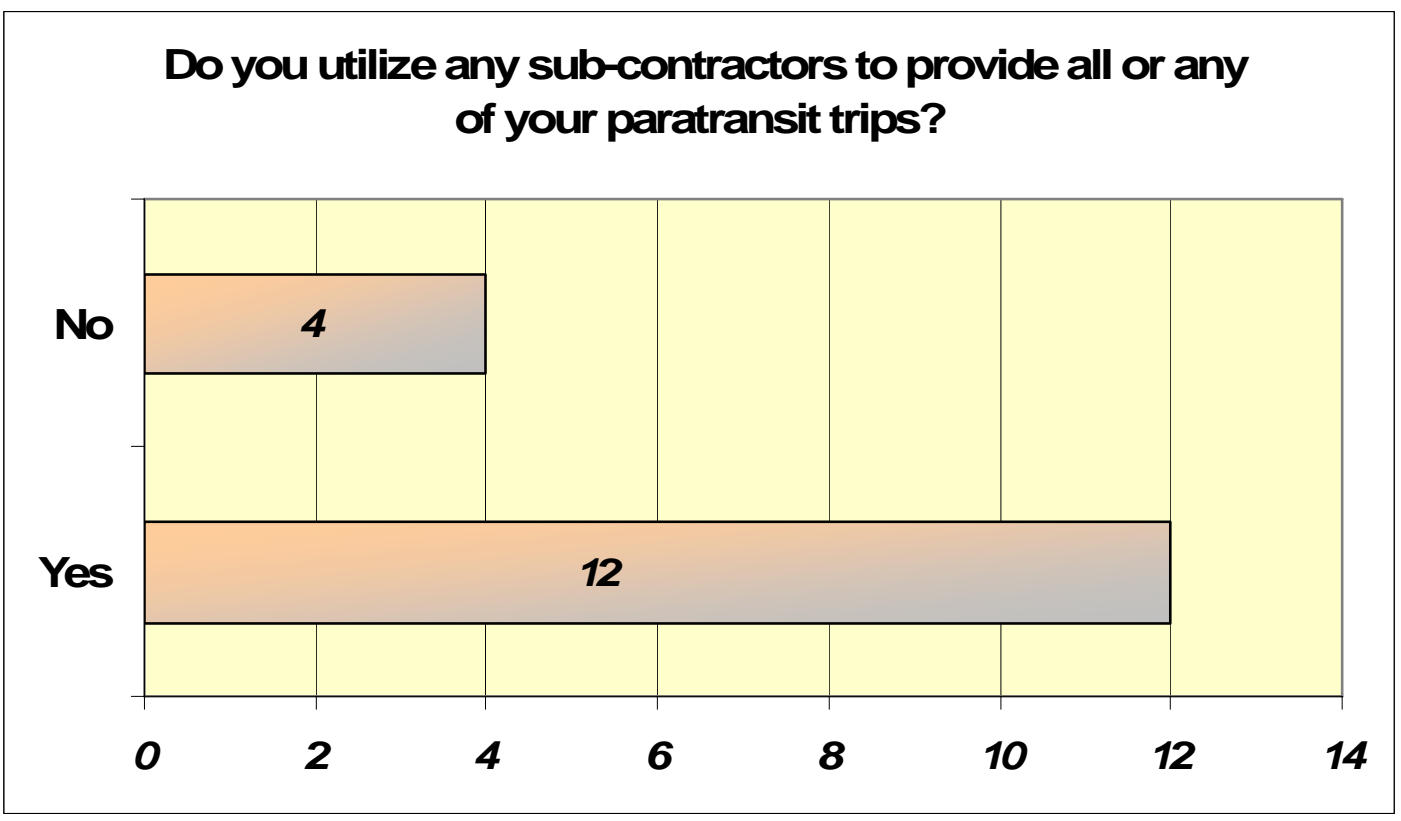

Another approach to maximize operating efficiencies is to utilize contractors to provide some or all the system's paratransit trips. Several systems provide some trips with in-house personnel, but contract out for the remainder of the trips. This helps accommodate fluctuations in demand and handling difficult trips due to location or time of day.

Exhibit 17 shows that 75 percent of the Florida systems responding indicated that they use subcontractors for some or all of their paratransit trips. When accounting for the contract management and oversight expenses, contracting services may or may not result in cost savings. If cost savings is the primary motive for exploring contracting options, a thorough cost analysis should be conducted.

\section{No-Show and Late Cancellation Practices}

As discussed previously, no-show passengers and late cancellations adversely impact the daily operation of all paratransit systems. No-shows are passengers that simply are not available to ride the paratransit vehicle as scheduled and do not provide any pre-notice of their 
unavailability. Late cancellations are those passengers that call to cancel their reservation but do so without adequate notice for the service provider to readjust its daily trip schedules.

The failure of scheduled passengers to be available to ride creates unproductive time for the system, lowers the quality of service for the other passengers, and could prevent other prospective passengers from effectively accessing the paratransit service. As the percentage of no-show and late cancellations trips rise, the system productively is impacted and the quality of service for all other passengers suffer.

While some no-shows and late cancellations must be expected, transit agencies have the ability to take steps to manage and minimize such practices.

As mentioned previously, effective education of the paratransit passengers as to their responsibilities will pay off in efficiency dividends to the system. Similarly, techniques such as reminder telephone calls to some or all of their paratransit passengers can reduce the frequencies of no-show and late cancellations.

One critical step in the management of no-shows and late cancellations is for transit agencies to have official policies for each of these situations and to effectively monitor and enforce the policies. 
Exhibit 18

\begin{tabular}{|l|c|c|}
\hline Does your transit agency... & Yes & No \\
\hline Have an official No-Show Policy? & 15 & 1 \\
\hline Have an official Late Cancellation Policy? & 13 & 3 \\
\hline Routinely enforce these policies? & 13 & 3 \\
\hline $\begin{array}{l}\text { Ever suspend ridership privileges due to } \\
\text { violation of these policies? }\end{array}$ & 9 & 7 \\
\hline
\end{tabular}

Exhibit 18 summarizes the responses to four questions related to no-show and late cancellation policies. The majority of transit systems responding (81\% to $94 \%$ ) have and enforce policies. It should be noted that only 56 percent indicated that they had actually suspended ridership privileges due to violation of their policies.

\section{Use of Technology}

As technology is becoming more common in the paratransit industry, efficiencies in scheduling and service delivery are being realized by many transit agencies. A series of questions were included in the survey to determine the extent to which the Florida transit systems have taken advantage of the emerging technologies.

The three most prevalent paratransit technologies - beyond effective communication systems that impact productivity would be computerized scheduling software packages, automatic vehicle locator systems, and mobile data terminals. 
Exhibit 19

\begin{tabular}{|l|c|c|}
\hline Does your transit agency... & Yes & No \\
\hline $\begin{array}{l}\text { Use a compterized paratransit scheduling software } \\
\text { package? }\end{array}$ & 15 & 1 \\
\hline Have any Automatic Vehicle Locator systems? & 9 & 7 \\
\hline Have any Mobile Data Terminal systems? & 7 & 9 \\
\hline
\end{tabular}

Exhibit 19 indicates that almost all transit agencies (94\%) in Florida have computerized paratransit scheduling and reservation software systems in place. However, just over half (56\%) have installed either Automatic Vehicle Locator systems or Mobile Data Terminal systems.

\section{Exhibit 20}

\section{Type of Paratransit Scheduling Software Used}

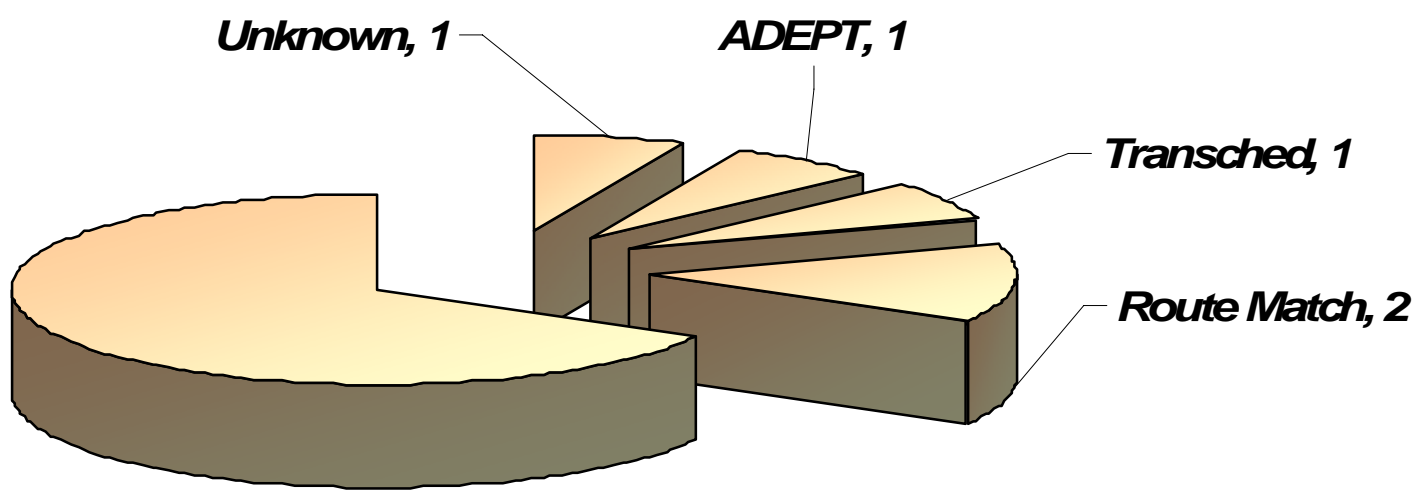

Trapeze, 10

Exhibit 20 details the brands of computerized paratransit scheduling systems used by the responding paratransit systems. Trapeze, with a 63 percent market share, is the predominant paratransit scheduling software package used in Florida. This may present opportunities for common training sessions and the organization of a user-network among these Florida transit agencies. 


\section{$\underline{\text { Travel Training and Use of Fixed Route System }}$}

One of the most effective and long-lasting techniques that can be employed is training and encouraging existing paratransit passengers to use the fixed route transit service in their community. This is a win-win proposition for both the transit system and the individual. The transit system is able to use excess capacity on its fixed route system at minimal cost to the agency. With the ability to use the fixed route system, the passenger can access a wider variety of services, does not have to pre-schedule his/her travel, and usually realizes cost savings in terms of lower fares.

The survey included some questions to determine the current practices utilized to encourage greater use of the fixed route transit services by paratransit passengers.

\section{Exhibit 21}

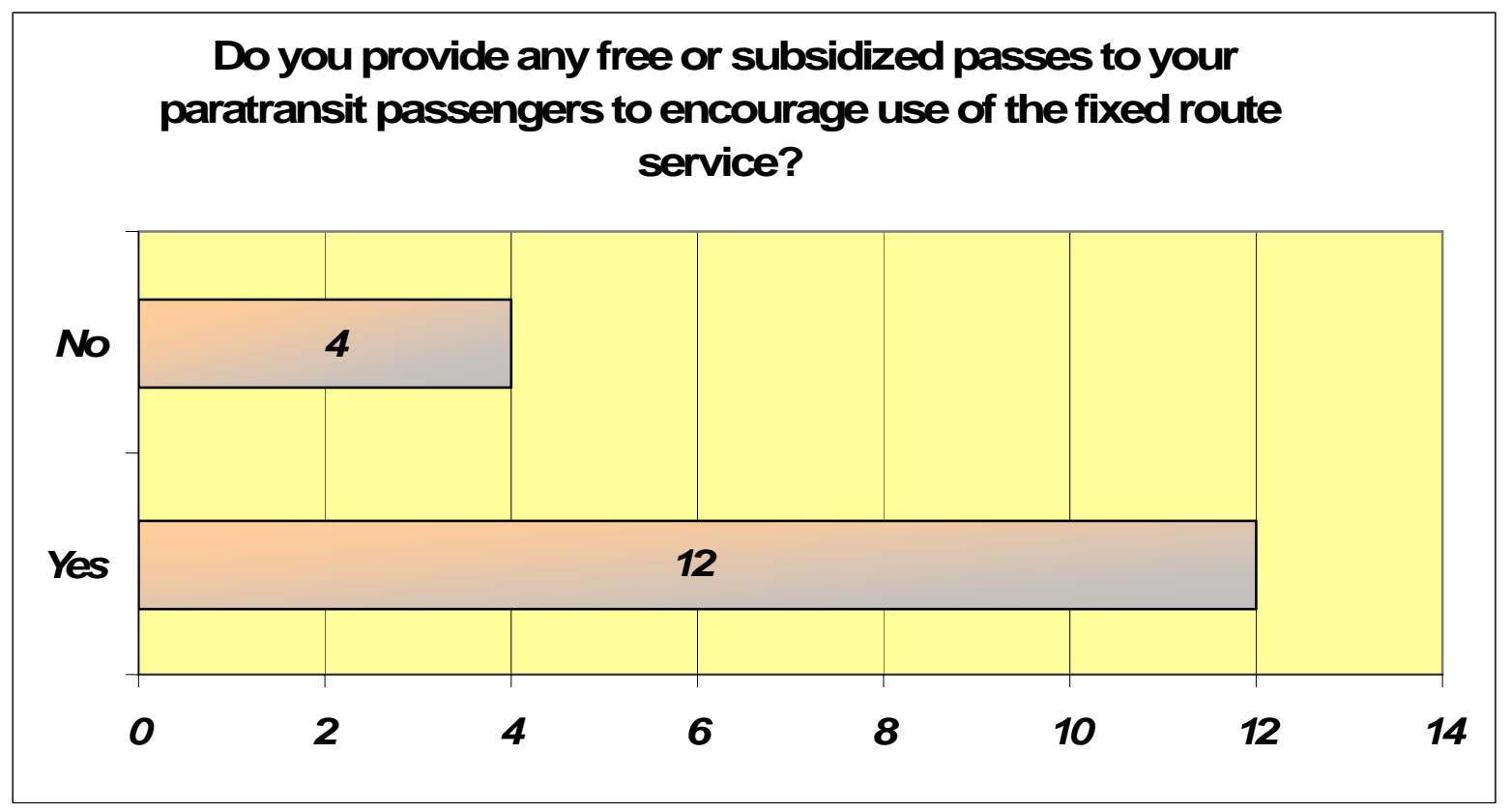

One method to encourage paratransit passengers to use the fixed route bus service is to offer free or reduced fares. As noted earlier in the report, the annual savings to the transit agency can be significant - even for shifting a single passenger from the paratransit service to the fixed route system. 
Exhibit 21 reveals that 75 percent of the responding Florida transit agencies use this costcontainment strategy.

\section{Exhibit 22}

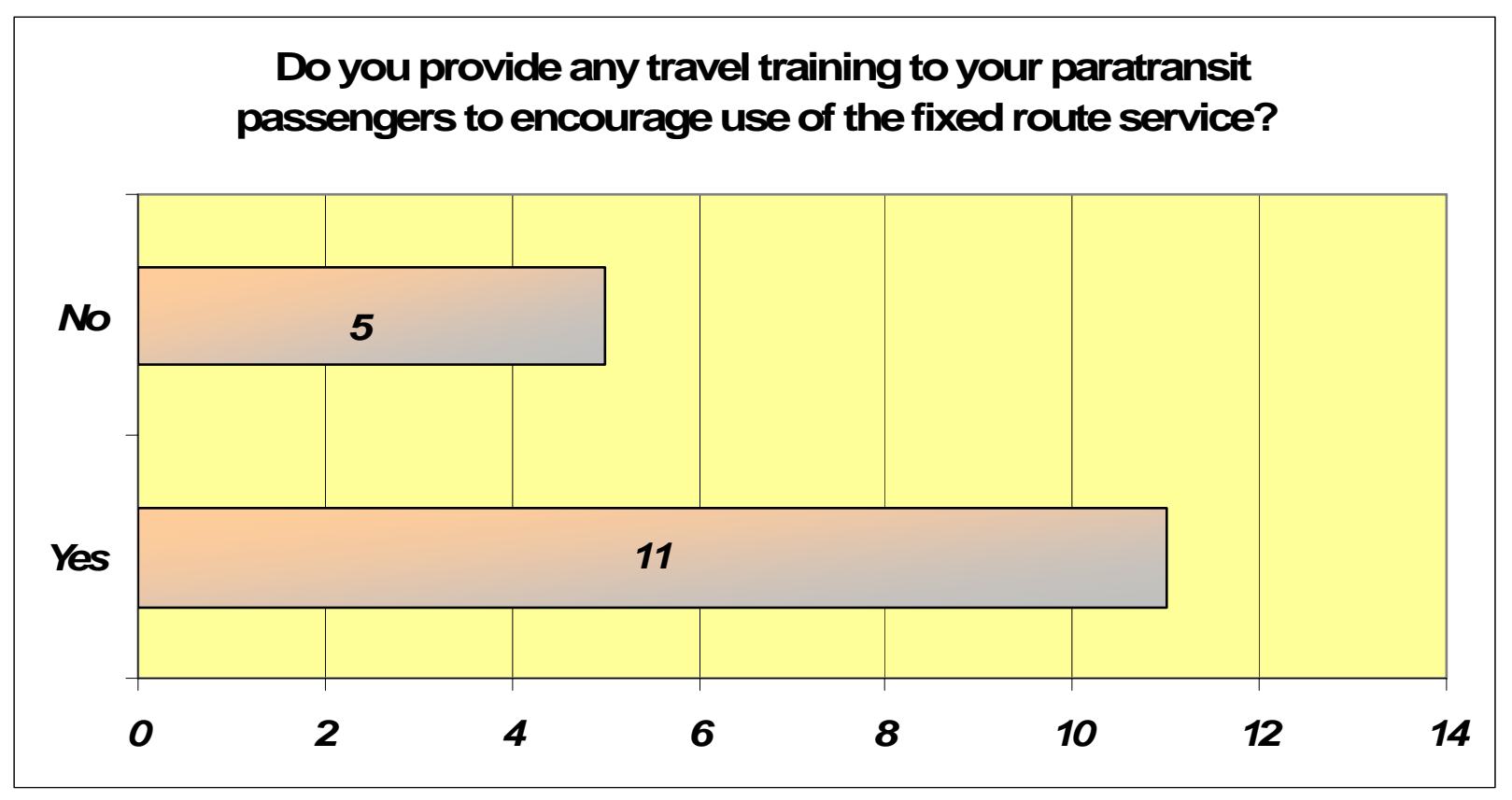

Another proactive strategy employed by transit agencies to encourage greater use of the fixed route system by paratransit passengers is to provide varying degrees of travel training. Almost 7 in 10 of the Florida transit agencies provide some form of travel training. 


\section{Volunteer Programs}

One of the final areas of cost management strategies explored in the survey was to look at the current practices in using volunteers in any facet of the paratransit service provision.

\section{Exhibit 23}

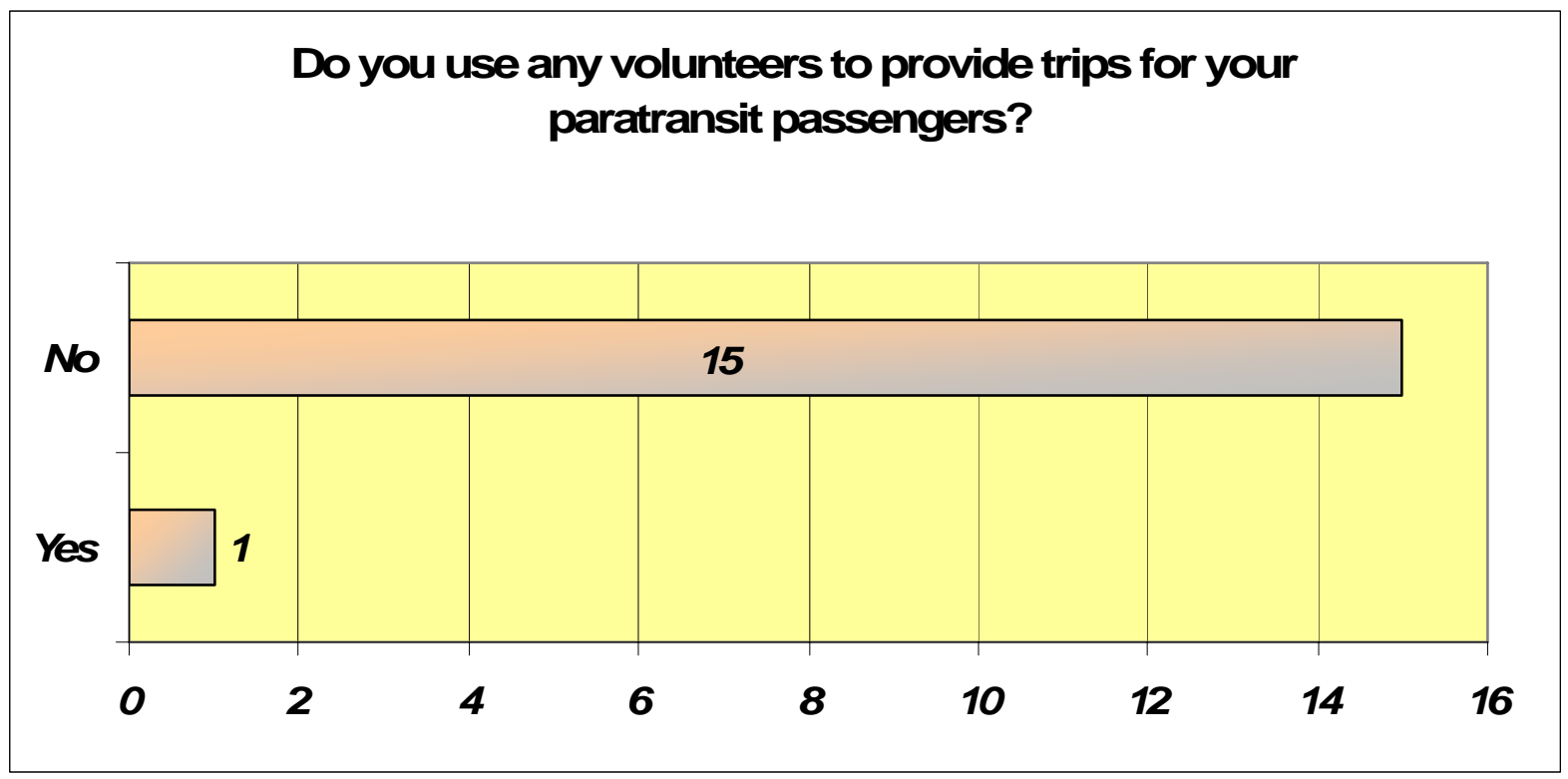

As detailed in Exhibit 23, surprisingly few Florida transit systems have any programs to use volunteers in any aspect of the delivery of paratransit services. Sarasota is the one exception, utilizing two volunteer bus riding trainers and one clerical position. 


\section{Chapter Five}

\section{Best Practices}

When this research project was initiated, it was hoped that some critical insight into the cost factors of providing paratransit services would be uncovered, leading to the discovery of innovative and breakthrough cost containment strategies. These hopes and aspirations, however, were not realized. While the major cost components of paratransit services were identified, the strategies and best practices for managing the costs of paratransit services came down the application of good management policies and practices, a comprehensive approach to address multiple cost-containment strategies, and ongoing and continuous vigilance of the process.

\section{Cost Containment Strategies}

This chapter provides a summary of the best practices that were identified for managing and containing the costs of providing paratransit services. These strategies and practices are organized by topical areas and presented in abbreviated format so as not to repeat the background presented in the previous chapters.

\section{$\underline{\text { Service Areas }}$}

- Transit agencies should be deliberate in defining the service areas where paratransit services are provided. Due to the special needs of many of the potential passengers, the tendency is to be all-inclusive and attempt to serve everyone, including those passengers outside the three quarter mile corridor surrounding fixed routes.

- It is recommended that the service area for complementary ADA paratransit service be set at the minimum allowable by FTA. This would be to limit ADA-sponsored service to those areas within $3 / 4$ mile of the existing fixed route service and only for trips with an origin and destination within that service corridor. Similarly, ADA-sponsored trips should be limited to the same service spans as the fixed route service. 
- Paratransit service outside the minimal ADA service area can still be provided by the transit agency, but the transit agency will be able manage such trips through differing trip charges, applying travel priorities, and similar measures either not allowed or limited by the ADA regulations.

\section{Eligibility Process}

- After determining the service area boundaries (both spatial and temporal), the next critical step in managing the costs of providing paratransit service is controlling the demand for the service. This can be managed to some degree through the eligibility process.

- The application form itself is a critical element in the eligibility process, especially for the complementary ADA paratransit sponsored passengers. Most agencies use paper application forms.

- The ADA application form should be designed to be ADA compliant (e.g., large type fonts) and request enough applicant information necessary to determine if they meet the minimum eligibility criteria. Since final determinations are based on functional abilities as well as the applicant's medical condition, questions should be included to probe the applicant's ability to use the fixed route bus service.

- In addition to the applicant's self-assessment and descriptions, most application forms also include a medical verification section that must be completed and submitted by the applicant's physician.

- Many transit agencies have added a functional assessment phase to the eligibility process. Functional assessment practices vary widely in frequency and comprehensiveness. Some transit agencies require all applicants to come in for a faceto-face visit and interview, which may include some physical assessments to determine that applicant's ability to use the fixed route bus service. On the other hand, many transit agencies require this only when an eligibility decision can not be made based on the application alone. 
- In-person functional assessment practices are often determined by considerations related to the time and costs associated with the process. The question that each agency must answer is determining the balancing point between cost of the assessment process and the amount of benefits (i.e., cost savings) realized.

- It must be remembered that all eligibility processes must have an appeal process.

\section{$\underline{\text { Recertification }}$}

- It is recommended that transit agencies undertake recertification of all paratransit passengers on regular basis. This will allow agencies to fine tune their application and certification process, incorporate any changes in policies and practices, and update their client lists to account for changes in status, relocations, and deaths.

- The frequency of the recertification is a local decision and may be driven by staff time and the related expenses of the process. As detailed in the survey findings, three years was found to be the most common recertification cycle.

\section{$\underline{\text { Reservation / Scheduling / Dispatching Process }}$}

- Once the decision is made on service area and eligible passengers, the next key component in the management of paratransit costs is the development of an effective and efficient reservation/scheduling/dispatch process.

- Agencies that have a well coordinated reservation/scheduling/dispatch process will have a much better handle on the ever increasing costs of providing paratransit transportation services. Ideally, an agency should establish a smooth call intake process, develop an attainable operational schedule, and implement a dispatch process where all operators have direct communication with the control center will be most effective. Failure to provide any of these key components will limit an agency's effectiveness in effective service delivery and cost containment. 


\section{$\underline{\text { Reservation System }}$}

- Each agency must establish a reservation process and communicate it to the patrons. Reservation windows are created to ensure riders get to their destinations at the necessary time for appointments. When calling for a pick-up time, it is important for both the reservationists and the patron to discuss actual pick-up time versus appointment times. Most agencies in Florida now establish 30-minute or greater pick-up windows.

- Where possible, the reservationists should be given the authority to negotiate pick-up and drop-off times. This benefits the transit agency by smoothing out the demand. Passengers benefit by having greater flexibility and reliability.

- During the reservation process, it is essential that the reservationists verify the passenger's information, including pick-up and drop-off locations and scheduled pick-up and drop-off times that were agreed to.

- It is important for the patron to understand the actual policies regarding pick-up and drop-off windows. Many transit agencies have developed rider guides that go step-bystep through the process of reserving and using paratransit services. Appendix B provides an example of an excellent and comprehensive paratransit service rider guide from VOTRAN, the public transit agency providing service to Volusia County, Florida.

- The rider guides are an excellent passenger information resource that not only detail the service, its policies and procedures, and provides key information, but also provides the agency with an opportunity to educate the passenger about their responsibilities and expectations.

- Many agencies have subscription service trips that make up a portion of their trip requests. Subscription service trips generally are trips that a patron makes multiple times per month, often multiple times per week, and are of a specific origin and destination that does not change. Most often, these types of trips are for employment, medical, and/or educational purposes. These trips can be prescheduled and reduce the burden on the call in-take system. 


\section{Scheduling}

- Agencies utilizing an automated scheduling system will have each day's schedule (i.e., often referred to as the trip manifest) developed via computer. However, it is critical that the daily schedule be reviewed by experienced employees to review the proposed schedule and make the necessary adjustments. The automated system can only produce a schedule based on the parameters set by the transit operator, so the staff charged with scheduling and dispatch must have some ability to manage or override the automated system should it be necessary.

- Some systems call some or all of their passengers prior to their scheduled trips to remind them of their reservation. This helps reduce the no-shows and late cancellation rates and results in more efficient service.

- Permitting same day scheduling of paratransit trips has been successfully implemented in some systems. Among the benefits realized are improved customer service, lowering pent up demand, and reducing the practice of some passengers to book extra trips to keep their future travel options open and later canceling unneeded trips.

\section{Dispatching}

- The dispatch system at the transit agency is the operation center for paratransit operations. It is essential that the dispatch operation has direct communication with the paratransit vehicles and operators. Dispatchers must be on call to deal with any changes or disruptions that the paratransit system encounters. One of the key duties for dispatch operations is to know where the vehicles and the operators are at all times, should it be necessary to re-route or adjust the passenger manifest with deletions and additions.

- Individual agencies should each have a policy process in place to monitor where the operators are during the daily schedule. Some agencies have systems where the vehicle operator will check in with the dispatcher at each pick-up and drop-off location. This provides an open line of communication, alerts the dispatch center to any abnormalities 
the operator is facing (running late, arrived too early, patron no-show), and allows the dispatcher to adjust the schedule as necessary.

- For larger systems, this type of driver check-in may not feasible as there are too many vehicles operating at one time. Often, larger systems will utilize a system where vehicle operators contact the dispatch center only in the event of a problem (running late, noshow), so that dispatchers can make the necessary adjustments to the schedule.

- As noted below, the installation Mobile Data Terminals (MDT) and Automatic Vehicle Locator (AVL) systems greatly aids the dispatching and operations control process.

\section{Use of Technology}

- The investment in and use of technology can provide the transit agency with significant efficiencies. This would include, but not be limited to:

o A sophisticated telephone system

o State-of-the-art vehicle communication system

o Reservation and scheduling computer software systems

o Automatic Vehicle Locator (AVL) systems

o Mobile Data Terminals (MDT) systems

- Phone systems can improve and monitor the call in-take process. It is critical that the phone system can handle the volume of calls in a timely manner. Features such as automatic call distribution spreads the calls evenly to the in-take personnel and allows for monitoring of performance such as average time waiting, average call length once connected, dropped calls, and other key performance measures.

- Paratransit software packages facilitate the entire process from creating data bases of eligible passengers, determining trip eligibility, scheduling the trip, developing the trip manifests, monitoring trips made, and producing invoices. 
- Agencies using an automated scheduling system will have each day's schedule developed via computer. However, it is critical that the daily schedule be reviewed by employees to verify the process. The automated system can only produce a schedule based on the parameters set by the transit operator, so the staff charged with scheduling and dispatch must have some ability to manage the automated system should it be necessary.

- When coordinated with the reservation software, automated phone systems allow for reminder or verification calls to the patron on the day prior to or day of travel.

- Automatic Vehicle Location (AVL) systems permit the dispatchers and supervisors to know the location of all paratransit vehicles in service, thus permitting effective oversight and improved responses to required rescheduling.

- When the various technologies such as AVL are all in place, Mobile Data Terminal (MDT) systems can be used, taking the paratransit service delivery to the next level. MDTs provide the operators with paperless or electronic manifests (usually their next four trips), allow the operators to record pick-up and delivery times and locations with a touch of a button, keep logs of times and mileage, and allow automated record keeping. Dispatchers have the capability of deleting, adding or reassigning trips to respond to cancellations, traffic conditions, and other incidents.

- MDTs provide documentation of no-show. Some MDTs provide mapping capabilities allowing the operator to locate pick-ups and destinations, as well as routings between each.

- MDTs eliminate the paperwork associated with the trip manifest process and increases efficiency by eliminated re-writing and re-entering trip data. Accessible Services in Seattle, Washington, was able to realize a seven percent in productivity after installing MDTs. This resulted in cost savings that paid back the full cost of the system within 3 years. 


\section{No-Shows and Late Cancellation Policies}

- One of the most common ways that a daily paratransit schedule gets disrupted is by passengers with no-shows and late cancellations. No-shows are passengers that simply are not available to ride the paratransit vehicle as scheduled and do not provide any prenotice of their unavailability. Late cancellations are those passengers that call to cancel their reservation but do so without adequate notice for the transit agency to readjust its daily trip schedules.

- Of the two, no-shows have the greatest impact on paratransit operations. The failure of scheduled passengers to be available when scheduled to ride creates unproductive time for the system, lowers the quality of service for the other passengers, and could prevent other prospective passengers from effectively accessing the paratransit service. Additionally, unless the service provider has the policy of charging patrons for their noshows or late cancellation trips, the provider also realizes the loss of the revenue (both the passengers and the sponsoring agency fees).

- While an occasional trip cancellation or no-show is understandable, the transit agency should develop strict policies on the occurrence of such practice, and should enforce penalties (e.g., suspension of travel privileges) if a patron is found to abuse the system.

- Agencies should be proactive in monitoring their no-show and late cancellation rates, documenting the occurrences and notifying the offending passengers in accordance with their policies. In Reno, Citifare developed a carrot and stick that provided free bonus rides to those paratransit passengers with perfect records, while addressing the offending passengers by charging them for their no-show trips and issuing suspensions of service for excessive no-show and late cancellations. After the first year of instituting this policy, Citifare was able to provide more rides, no-shows decreased dramatically, denied trips decreased, some additional revenues were realized, and customer satisfaction increased. 
- While not meant to replace other processes, a best practice technique is to have the operator complete and fill out a door hanger that documents their attempt to pick up the passenger, reminds the passenger of their responsibilities, and provides a contact telephone number.

\section{Contracting}

- An approach to maximize operating efficiencies is to utilize contractors to provide some or all the system's paratransit trips. Several systems provide some trips with in-house personnel, but contract out for the remainder of the trips. This helps accommodate fluctuations in demand and handling difficult trips due to location or time of day.

- If the decision is made to contract out some or all of the paratransit trips, it is essential that adequate service provider reviews are incorporated into the contract. This should include service delivery monitoring, customer satisfaction feedback, vehicle inspections, review of safety and accident records, review of driver files, and similar quality control measures.

- When accounting for the contract management and oversight expenses, contracting services may or may not result in cost savings. If cost savings is the primary motive for exploring contracting options, a thorough cost analysis should be conducted.

\section{$\underline{\text { Service Monitoring }}$}

- By its nature, paratransit service is difficult to effectively monitor and requires special efforts by the agency to ensure safe and effective service delivery. Effective monitoring will ensure quality service at the most cost effective level, prevent contractual fraud, and provide safe service delivery for passengers who often the most vulnerable.

- A service performance system should be developed to measure a variety of elements, ranging from the call in-take process, on-time performance, vehicle readiness, noshows, productivity measures, etc. 
- A formal system to monitor complaints and compliments should be implemented and continuously maintained. All complaints should be investigated and responded to in a timely manner.

\section{$\underline{\text { Use of Fixed Routes }}$}

- As detailed in the recommendations about setting the service area and determining eligibility, the key in the management of paratransit costs is managing the demand for paratransit service. The use of the fixed route system by patrons in lieu of the paratransit system provides a great opportunity to not only manage costs, but also to expand the travel and mobility options for the passenger.

- Working with the fixed route service operator, some of the proactive steps that can be undertaken to encourage use of the fixed route system include:

o Provide accessible information

o Improve the accessibility to and from the bus stops

o Invest in passenger amenities at the bus stop

o Continue to improve the vehicle accessibility and ability to accommodate passengers with special needs

o Ensure the announcement of bus stops by the bus operators

o Encourage the installation of automatic stop announcement systems

\section{Fixed Route Travel Training}

- One of the most effective and long lasting techniques that can be employed is training and encouraging existing paratransit passengers to use the fixed route transit service in their community. This is a win-win proposition for both the transit system and the individual. The transit system is able to utilize excess capacity on their fixed route systems at minimal costs to the agency. With the ability to use the fixed route system, the passenger can access a wider variety of services, does not have to pre-schedule their travel, and usually realizes cost savings. 
- Transit agencies should be proactive in encouraging paratransit passengers to use the fixed route services through such as actions as:

o Offering free or reduced fares for the fixed route service for eligible paratransit passengers as an incentive

o Provide group and one-on-one travel training

o Identifying prospective fixed route passengers though the eligibility process

o Utilizing Mobility Mangers to provide the training

\section{$\underline{\text { Use of Volunteers }}$}

- Volunteers offer a relatively untapped resource to offset some of the paratransit system operating expenses. While there may be limitations in the actual delivery of service, volunteers can assist with travel training, customer information, and many of the behindthe-scenes clerical functions. 


\section{References}

AGENDA-Paratransit Working Group, , San Francisco County Transportation Authority, September 19, 2005

Anchor Rides, Municipality of Anchorage, Alaska People Mover, 2002

Comparison of Capital Costs for Fixed-Route Bus Stop Improvements to Paratransit Operating Cost, Maryland MTA, Baltimore, 2007.

Demand Response Definitions. American Public Transportation Association, 2003.

Easter Seals Project Action: ADA Complementary Paratransit: A Decade of Innovation, December 2002.

Easter Seals Project Action: Innovative Practices in Paratransit Services, 2002.

Eligibility Requirements for ADA Paratransit Service, 9 Oct. 2003.

Kack, David and Phillip, Deepu, An Evaluation of RouteMatch Software in the Billings MET Special Transit System, Western Transportation Institute, Montana State University, May 2007.

Koffman, D., Lewis, D., Forecasting Demand for Paratransit Required by the Americans with Disabilities Act, Transportation Research Record 1571, 1997.

Menninger-Mayeda, et.al., ADA Demand Forecasting for Orange County Transportation Authority's Access Program, January 2004.

Minutes-Paratransit Working Group (PWG), San Francisco County Transportation Authority., September 19, 2005.

Research Results Digest 75-Executive Summary: Cost Benefit Analysis of Providing NonEmergency Medical Transportation, Transit Cooperative Research Program, January 2006

S.G. Associates, et. al., Workbook for Estimating Demand for Rural Passenger Transportation, Transit Cooperative Research Program, TCRP Report 3, 1995.

Spending Tomorrow's Dollars On Yesterday's Problems.

"Status of MUNI Activities and Issues Related to Paratransit Costs." September 19, 2005.

TCRP Report 38: Guidebook for Evaluating, Selecting, and Implementing Fuel Choices for Transit Bus Operations, Transit Cooperative Research Program, 1998.

TCRP Report 49: Using Public Transportation to Reduce the Economic, Social, and Human Costs of Personal Immobility, Transit Cooperative Research Program, 1999. 
TCRP Report 61: Analyzing the Costs of Operating Small Transit Vehicles, Transit Cooperative Research Program, 2000.

TCRP Report 91: Strategies for Achieving the Economic Benefits of Coordinated Transportation Services,

TCRP Report 101: Toolkit for Rural Community Coordinated Transportation Services, Transportation Cooperative Research Program, 2004.

The T (Fort Worth Transportation Authority Mentor Engineering, 2006.

TRANSPORTATION SYSTEM: Transit and Transportation Disadvantaged, Trends and Conditions Report-2006, May 2006.

Volinski, Joel, "Lessons Learned in Transit Efficiencies, Revenue Generation, and Cost Reductions", National Center for Transit Research at CUTR, 2003.

Volinski, Joel, "A Review of the Cost Benefit of Mobile Data Terminals in Paratransit Operations", Center for Urban Transportation Research, 2003.

Weiner, Richard, Poultney, N., Perrone, B., King County Keeps Moving: Evaluating Best Practices in ADA Paratransit Eligibility, American Public Transportation Association, 2004. 
APPENDIX A - Survey Instrument 


\section{Survey of Practices for Managing Paratransit Costs}

As part of our NCTR project entitled "Creative Ways to Manage Paratransit Costs", we are surveying the Florida public transit agencies to identify your existing practices and efforts to manage and contain paratransit costs.

In consideration of your time and busy schedules, the survey is designed to allow simple yes/no and quick responses. No statistics or financial data is requested.

We would appreciate if the you or the person in your organization most familiar with your agencies paratransit program, including your complementary ADA paratransit services, would complete the survey and return it by email to my attention (jaygoodwill@cutr.usf.edu) on or before Wednesday, November $14^{\text {th }}$.

Thank you in advance for your assistance. All of your response will be kept confidential. All reported data will be a compilation of all responses received and not attributed to any specific system.

AGENCY:

PERSON COMPLETING SURVEY:

Name:

Title:

Telephone Number:

E-mail Address:

\section{CERTIFICATION PROCESS}

1. Has your agency made any changes to your ADA Paratransit Certification Application in the past five years?

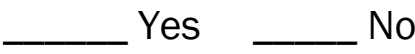

If Yes, please provide further detail:

2. Does your agency recertify your ADA Paratransit passengers on a regularly scheduled basis? Yes

If Yes, how often to you recertify?

Annually

Bi-annually

Every 3 years

Other: please provide details: 
3. Does you agency perform in-person assessments for ADA Paratransit applicants? Yes $\quad$ No

If Yes, what percentage of the applicants must undergo the assessments?

Response: $\%$

Provide further detail if applicable:

\section{SERVICE AREA DEFINITIONS}

4. Do you restrict your ADA Complementary trips to the minimal $1 / 2$ mile corridor definition?

Yes _ No

5. Do you impose any other restrictions for your ADA Complementary trips in addition to the minimal $1 / 2$ mile corridor definition?

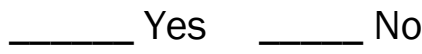

If Yes, please provide further detail:

\section{TRIP PRIORITAZATION AND MANAGEMENT}

6. For your non-ADA Complementary paratransit trips, do you utilize any trip prioritization criteria to deny any requested trips?

Yes

If Yes, please provide further detail:

7. Do you allow same day scheduling of paratransit trips?

Yes _ No

If Yes, please provide further detail:

8. What is your pick-up window?

Please provide detail: 
9. Does your system provide any "reminder calls" to paratransit passengers reminding them of their scheduled trips? Yes No

If Yes, please provide further detail:

10. How does your system provide most of your paratransit trips?

Curb-to-Curb

Door-to-Door

Thru Door-to-Thru Door

11. Do your reservationists or dispatchers "negotiate" pick-up times with your paratransit passengers?

$$
\text { Yes No }
$$

If Yes, please provide further detail:

12. Does your system utilize sub-contractors to provide any or all of your paratransit trips?<smiles>C[AsH2]N=O</smiles>

If Yes, what percent of the trips: $\%$

NO SHOW AND LATE CANCELLATION PRACTICES

13. Does your system have an official "No Show" policy? Yes No

If Yes, please provide further detail:

14.Does your system have an official "Late Cancellation" policy? Yes $\quad$ No

If Yes, please provide further detail:

15. Does your system routinely enforce your "No Show" or "Late Cancellation" policies? Yes No

If Yes, please provide further detail: 
16. Has your system ever revoked or suspended ridership privileges as a result of enforce your "No Show" or "Late Cancellation" policies?

Yes

No

If Yes, please provide further detail:

\section{USE OF TECHNOLOGY}

17.Do you utilize a computerized paratransit scheduling package to register and schedule your paratransit trips?

Yes No

If Yes, what software system do you use:

18. Does your system have any "Automatic Vehicle Locator (AVL)" systems?

Yes

If Yes, for what percent of your paratransit fleet:

19.Does your system have any “Mobile Data Terminal” systems?

$$
\text { Yes }
$$

No

If Yes, for what percent of your paratransit fleet:

\section{TRAVEL TRAINING AND USE OF FIXED ROUTE SYSTEM}

20. Does your system provide any free or subsidized passes to your paratransit passengers to encourage their use of your fixed route system?

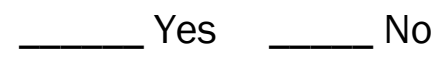

If Yes, please provide further detail:

21. Does your system provide any "travel training" to your paratransit passengers to encourage their use of your fixed route system?

Yes _ No

If Yes, please provide further detail: 
22. Does your system make efforts to improve the accessibility of the fixed route bus stops to encourage greater utilization by paratransit passengers?

Yes $\quad$ No

If Yes, please provide further detail:

\section{VOLUNTEER PROGRAMS}

23. Does your system use any "volunteers" to provide trips to your paratransit passengers?

$$
\text { Yes No }
$$

If Yes, please provide further detail:

\section{OTHER IDEAS AND PRACTICES}

24. Do wish to share any other techniques or practices that your system employs to help manage and control the costs associated with providing paratransit trips?

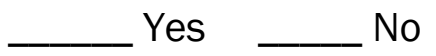

If Yes, please provide further detail:

THANK YOU FOR TAKING THE TIME TO HELP US WITH THIS PROJECT!

If possible, please complete the survey and return it by email to the attention of Jay Goodwill at CUTR (jaygoodwill@cutr.usf.edu) on or before Wednesday, November 14 ${ }^{\text {th. }}$

Please send your competed surveys to:

Jay Goodwill - USF Center for Urban Transportation Research

jaygoodwill@cutr.usf.edu

813-974-8755 
APPENDIX B - Example of a Rider Guide 


\title{
VOTRAN GOLD USER GUIDE
}

\author{
RESERVATIONS \\ EAST VOLUSIA: (386) 322-5100 \\ WEST VOLUSIA: (386) 943-7050 \\ SOUTHEAST VOLUSIA: (386) 424-6810 \\ CUSTOMER SERVICE \\ (386) 756-7496 \\ TDD \\ (386) 756-7494 \\ RESERVATIONS FAX \\ (386) 322-5119 \\ THIS GUIDE IS AVAILABLE IN AN \\ ACCESSIBLE FORMAT UPON REQUEST
}

OCTOBER 2005 


\title{
VOTRAN MISSION STATEMENT
}

\author{
VOTRAN'S MISSION IS TO IDENTIFY AND SAFELY \\ MEET THE MOBILITY NEEDS OF VOLUSIA COUNTY. \\ THIS MISSION WILL BE ACCOMPLISHED THROUGH A \\ COURTEOUS, DEPENDABLE, COST EFFECTIVE AND \\ ENVIRONMENTALLY SOUND TEAM COMMITMENT TO \\ QUALITY SERVICE.
}




\section{INTRODUCTION}

Votran Gold Service is a door-to-door shared-ride Paratransit Service. Since the service is provided from door-to-door, you must be on the ground floor to be picked up for your transportation. In addition, sharedride means your trip could involve stopping to pick up or drop off other customers along the way.

This special service is provided only for those individuals who cannot use Votran regular fixed route bus service because of a disability or when fixed route service is not available in your area and you have no other means of transportation.

To become qualified for this special service a completed application must be submitted to Votran for processing and determination of eligibility.

When making a reservation for service, please keep in mind a local trip (within the same service area) can take up to one hour. Trips from one service area to another can take up to two hours.

\section{Who is eligible to use Votran Gold?}

Votran Gold is intended to serve a limited group of people, specifically those sponsored under the following:

- Americans with Disabilities Act (ADA): Those individuals who reside within $3 / 4$ mile of an established bus route, but cannot use Votran regular fixed route service because of a disability.

- Transportation Disadvantaged (TD): Includes qualifying individuals located in areas where fixed route service is not available and who have no other means of transportation. 
- Medicaid: Votran Gold provides trips for Medicaid eligible services for those persons who cannot travel by fixed route and have no other means of transportation.

- Agencies: Includes people whose trips are funded under a negotiated agency contract.

Votran staff will determine the funding category appropriate for each customer. If you have questions about your eligibility status, please call Votran staff at (386) 756-7496.

\section{What groups make up Votran Gold?}

Votran Gold Service is made up of the following:

- A Transportation Disadvantaged Local Coordinating Board (TDLCB): The TDLCB is established under Florida Statute to oversee the delivery of paratransit services, resolve customer disputes and monitor quality of service.

- The Community Transportation Coordinator (CTC): VOTRAN acts as the CTC for Volusia County, coordinating and providing many of the transportation needs for ADA, TD and Medicaid eligible customers.

- Private Contractors: These operators provide paratransit services under contract with Votran.

To explain the services offered to you by Votran Gold, we have prepared the following USER GUIDE to help plan your trips and to make your transportation run as smoothly as possible. It is important that you take the time to read this guide completely to avoid any misunderstandings about the services offered by the system.

ii 


\section{OVERVIEW OF SERVICES}

Although Votran Gold serves all of Volusia County, certain restrictions may apply to the trips provided. These limitations may impact the times you can travel or the destinations that may be available to you.

\section{SERVICE AREAS}

The provision of Gold Service for Volusia County is divided into four service areas. They are defined as follows:

EAST VOLUSIA - Ormond Beach, Ormond-by-the-Sea, Holly Hill, Daytona Beach, South Daytona, Port Orange, Daytona Beach Shores, Wilbur-by-the-Sea and Ponce Inlet.

SOUTHEAST VOLUSIA - New Smyrna Beach, Edgewater and Oak Hill.

WEST VOLUSIA - Osteen, Enterprise, Cassadaga, DeLand, Orange City, Debary, Deltona, and DeLeon Springs.

NORTHWEST VOLUSIA - Astor, Barberville, Pierson, and Seville.

What service is available for trips in between service areas?

Trips between service areas are very limited and it is important to check the times of operation before you schedule your appointments. Please call the Reservation Department to determine what times the vehicles operate between Service Areas. 


\section{DESTINATIONS}

Votran Gold service provides specialized transportation throughout Volusia County. However, some travel limitations may exist based on the category of each qualified applicant. It's important that each of our customers understand the services available to them.

\section{Where may I travel?}

Depending on the program you are eligible for, some service restrictions may apply as a result of Federal or State regulations.

Customers who qualify for service under ADA may only schedule trips that begin and end in the ADA Corridor. The corridor is an area within $3 / 4$ of a mile on either side of a fixed bus route. While you may be certified to ride Votran Gold, all destinations in the county may not be within the ADA corridor.

Votran Gold clients who qualify under the Transportation Disadvantaged program are those individuals located outside of the ADA corridor. These clients are permitted to schedule trips countywide.

Medicaid recipients may travel only to those services qualified under their program of coverage. This may include out-of-county trips with prior approval.

People traveling under Agency sponsored trips are only authorized to take trips as arranged by the particular agency sponsoring the trip. 


\section{SERVICE TIMES}

\section{EAST VOLUSIA}

6:00 a.m. - 6:00 p.m., Monday through Saturday

Limited service is available on Sunday and during evening hours.

WEST VOLUSIA \& SOUTHEAST VOLUSIA

6:00a.m. - 6:00 p.m., Monday through Saturday

\section{HOLIDAY SCHEDULES}

Votran does not operate on New Year's Day, Thanksgiving Day and Christmas Day. Limited service is available on Memorial Day, 4th of July and Labor Day. Please call our Reservation Department for further information on our Holiday Schedules.

\section{ELIGIBILTY}

While some people might prefer to use Gold Service rather than a fixed route bus, this specialized service is designed to assist those individuals who cannot access Votran regular fixed route bus service because of a disability or when fixed route service is not available in your area and you have no other means of transportation. In order to determine whether or not a person is best served with Votran Gold, an eligibility process has been established.

\section{THE APPLICATION PROCESS}

Any resident of Volusia County may request an ELIGIBILITY APPLICATION from Votran by calling one of the phone numbers printed on the front of this guide. The Eligibility Application must be FILLED OUT 
COMPLETELY to be considered for transportation services from Votran. If you need assistance completing your application Votran staff members are available to help. The completed application will be reviewed by Votran and a determination of eligibility will be made based on the information provided. A staff interview or assessment may be required to complete the process.

The eligibility process can take up to twenty-one (21) days to complete. If you qualify for Votran Gold Service, the scheduling of future trips is a quick and easy process.

\section{VISITORS WITH DISABILITIES}

Votran provides complementary paratransit service to individuals who travel to Volusia County and are eligible for services under the Americans with Disabilities Act (ADA). If these individuals have been certified as "ADA Paratransit eligible" by a public entity, that certification will be honored for up to 21 days. If they have not been certified as eligible by another public entity but claim that they are ADA Paratransit eligible, they are entitled to "presumptive eligibility" for up to 21 days. If service is needed beyond this period, individuals will be required to apply for eligibility in the area they are visiting.

\section{RECERTIFICATION REQUIREMENTS}

To ensure that we are able to provide the best possible service, Votran must maintain current and accurate records. Therefore our customers are subject to recertification every three (3) years (with the exception of temporary certifications). 


\section{TRAVEL ASSISTANCE}

Many of our customers require assistance during their travel. While Votran drivers are able to provide assistance to and from the vehicle, some customers require more personalized care. This section of the Guide addresses customer's needs that extend beyond the responsibility of a Gold operator.

\section{How old must someone be to use Votran Gold service?}

\section{AGE REQUIREMENTS}

Children under the age of six (6) years MUST have an escort. Children under the age of four (4) years and/or under the weight of $45 \mathrm{lbs}$. will be required to use a child restraint device. Due to the cost of purchasing, maintaining and replacing the devices and for sanitary reasons related to the transmittal of communicable diseases, these devices must be provided by the accompanying adult or escort.

\section{What if I need an assistant to travel with me?}

\section{PERSONAL CARE ATTENDANTS}

Children under the age of six (6) and individuals requiring special assistance while en-route must have an escort/personal care attendant (PCA). The PCA must be able to provide the necessary assistance to the passenger and will be transported free.

Only one PCA may ride free of charge. In cases where it is not evident the individual needs an escort, medical documentation stating the reason an escort is needed will be required. The PCA will be traveling with the 
passenger to assist with life-functions and to facilitate travel. Although a PCA may travel with a customer, the Votran Gold operator still has a responsibility to assist from door-to-door. Both the PCA and the rider must be picked up and dropped off at the same address.

A PCA request must be approved on the initial application in order to be eligible to travel with a rider. To be eligible for a PCA, a physician or other qualified professional must include this information on your application. The information provided must state the functional limitations that require you to have additional assistance. If your physical status changes after the application is approved without a PCA being authorized, and one is now required, a letter must be submitted from a physician or other qualified professional stating that you now require a PCA.

\section{When do we require a PCA or escort?}

Agencies who schedule trips for children under the age of six (6) will be responsible for providing escorts or bus aides if a parent or guardian does not accompany the child. A parent or guardian escorting an under-age child may not bring additional children unless the other children have a scheduled reservation and will be receiving a service. Gold vehicle operators are available to assist passengers from the door of their pick-up location to the door of their destination. However, we require that passengers needing additional attendance upon reaching their destination also travel with an escort.

\section{COMPANIONS}

One companion may accompany an ADA Paratransit eligible rider. However, both must be picked up and dropped off at the same address. Accompanying companions pay the same fare as the eligible rider (currently \$2.00.) When making a reservation, you must indicate a companion is traveling with you. 


\section{RESERVING YOUR TRIP}

Due to the volume of customers served by Votran Gold each day, trips must be called in ahead of time to allow for proper scheduling.

\section{Who do I call for service?}

\section{CONTACTING RESERVATIONS}

You may request a trip by calling the Reservations Department using the telephone numbers printed on the front of this guide.

Requests for NEXT DAY service must be called in by 4:00 p.m. on the day preceding your trip. Same day service is not available. Requests for Monday service should be called in no later than the previous Friday by 4:00 p.m.

Trips may also be booked up to two (2) weeks in advance by calling the reservation department between 7:00 a.m. and 6:30 p.m. or on Saturday.

\section{What do I do if the phone lines are busy?}

Because of the number of trip requests we receive on a daily basis, our phone lines are sometimes busy. When you call to make a reservation for service and hear a recording, please stay on the line and the next available reservationist will be happy to assist you. Please note that our busiest hours are from 8:00 am to 10:00 am and from 12:00 noon to 2:00 $\mathrm{pm}$. The best time to call during the week is between the hours of 10:00 am and 12:00pm or after $2: 00 \mathrm{pm}$ 
What information will I need to provide when I call to make a reservation?

\section{REQUIRED INFORMATION}

When you call for an appointment please have the following information available:

- Pick up location - name, phone number, address including building and apartment number, town or city and zip code.

- Destination

o Street address (including: town or city \& zip code)

- Phone Number

- Doctor's Name

- Office or Suite Number

- Name of Facility if applicable.

- Appointment Time and Return Time.

- Medicaid Number, if applicable.

- Please inform the reservationist if you require a personal care attendant (PCA) on your trip and specify whether the PCA is ambulatory or in a wheelchair.

- Also, please inform the reservationist of any additional travel requirements needed to schedule your trip such as traveling with a service animal.

- Return trip information - exact location and time (see section on return trips for details).

Always give the reservationist the time you need to be at your destination or the time of your health care appointment. Since your vehicle will pick up several customers, trips are scheduled based on your appointment time. There is a pick-up window that requires passengers to be ready up to one (1) hour in advance of their scheduled appointment time. This means that if you have a 9:00 a.m. appointment you may be picked up as early as 8:00 a.m.

If you are traveling from one service area to another, you should be ready for your trip two (2) hours prior to your appointment. 


\section{What about scheduling my return trip?}

\section{RETURN TRIPS}

When you schedule your transportation, you MUST also schedule your return trip. Return trips that are not scheduled in advance will not be accepted.

Votran will be better able to accommodate a change in your return trip if we are notified promptly. Please contact Votran as soon as possible to inform us about a change to your trip. If you are not ready at your scheduled return time you may have to wait for a return ride to become available. Therefore it's important to schedule your return trip late enough so that you are sure you will be ready when your vehicle arrives.

When making your doctor's appointment, please inform the physician's office that you are riding on public transportation and that you need to be ready to return when the vehicle arrives.

In most cases, you will be picked up at the same location you were dropped off. If for some reason the pick-up location is different, be sure to tell the reservationist exactly where you will be waiting for your return trip. The driver will be given this information and will be looking for you at that location. Do not leave the area or you could miss your ride.

Please be advised that the one (1) hour delivery window applies to all return trips.

If you are ready for your return trip more than one (1) hour before it is scheduled, you may contact Votran to request an earlier pick-up. If you wait more than one (1) hour after your scheduled pick-up time, call one of the phone numbers on the front of this guide and a representative will assist you. Calling within the pick-up window will not expedite your trip.

Vehicles will only stop at pre-determined origin and destination points. Drivers will not make additional stops except in an emergency. 


\section{SUBSCRIPTION SERVICE}

A standing order or subscription service can be established when a customer regularly travels to and from the same destination (three or more times a week) at the same times. You will save time by submitting a standing order; however you must contact the reservation department immediately if your plans change to avoid being charged with a cancellation or a no-show.

\section{When are the best times to ride on the system?}

The Votran system operates on the public roads and highways. Occasionally our vehicles will run behind schedule during periods of peak demand such as special events, during rush hour, or during inclement weather. Your trip will have fewer problems if you avoid peak travel periods.

\section{TAKING YOUR TRIP}

\section{FARE INFORMATION}

Fares will depend upon your sponsorship or funding source. Your reservationist will tell you the cost of your trip when your reservation is made.

The driver will collect the fare from you when you board the vehicle. You must have the exact change. Drivers do not carry money and will not make additional stops to get change. Failure to pay the appropriate fare may jeopardize your transportation eligibility.

Please do not tip the drivers.

One-way tokens are available in quantities of ten (10). For information on purchasing one-way tokens, please call our Customer Service Department. The phone number is listed on the front of this User Guide.

\section{What type of vehicle will pick me up?}




\section{DRIVERS AND VEHICLES}

Votran operates vehicles designed to accommodate ambulatory, wheelchair and stretcher customers. Please note: stretcher service is available for Medicaid customers only.

Gold Service drivers are not responsible for charging, connecting or disconnecting any equipment used by a customer. Please ensure all equipment is functioning properly and independently prior to starting your trip.

To achieve the goals of shared-ride transportation, customers are expected to share transportation with other customers. Customers may not request a specific transportation provider. When you request service, you may be scheduled to ride with one of the Private Contractors or one of the Votran vehicles.

All Votran and Contract Operator drivers are required to wear uniforms and picture identification badges. All vehicles are plainly marked with the name of the company in a prominent location.

Votran Gold provides door-to-door paratransit service. Our drivers are trained to help those who require assistance to and from the vehicle. We do not enter a person's home or a person's room at a living facility. In addition, we do not go above the first floor of a multi - family residence. The customer must be waiting on the ground floor in the lobby or at the main entrance.

Our vehicles are equipped to transport common wheelchairs (or scooters), however the customer must have their own wheelchair. A common wheelchair is one that does not exceed 30 inches in width and 48 inches in length (measured two inches above the ground) and does not weigh more than 600 pounds when occupied.

Wheelchair customers must be on the first floor with no more than one (1) step from the entrance of the residence to ground level. If there is more 
than one (1) step to negotiate, an accessible ramp must be installed in order to accommodate the customer. In addition, customers in wheelchairs must have an accessible boarding area on which the lift can safely be deployed and the area leading up to the boarding area must be firm to accommodate the approach to the wheelchair lift. Grass, gravel and soft sand are not acceptable surfaces. WHEELCHAIRS MUST BE EQUIPPED WITH FOOT RESTS.

Vehicles are equipped with a boarding wheelchair to accommodate those customers with limited mobility to board the vehicle. The boarding wheelchair is not to be used for a means of transportation, only to assist customers to board and alight the vehicle.

\section{OXYGEN TRANSPORT}

Travel with oxygen equipment is permitted providing that it is selfadministered and can be safely stowed when the vehicle is en-route. Votran operators and contracted vendors are not permitted to supply, connect or disconnect oxygen.

\section{PERSONAL BELONGINGS}

Passenger property that can be carried by the passenger and/or the driver in one trip and can be safely stowed on the vehicle shall be allowed to be transported with the passenger.

\section{WILL CALL}

From time to time, a passenger may not be ready to make their return trip when the Gold service vehicle arrives. If this happens, the passenger will be placed into "will call" status. This means that you must contact Votran when you are ready for your return trip and you will be picked up as soon as a vehicle is available. 
What if I decide not to travel after making an appointment?

\section{CANCELLATION AND NO-SHOW POLICY}

NO-SHOW: Occurs when a person has reserved a trip and then does not take the trip when the vehicle arrives. A no- show is also applied to a person who cancels their trip within one (1) hour of the scheduled pick-up time.

SAME DAY CANCELLATION: Occurs when a person has reserved a trip and then cancels the trip on the same day it was scheduled, but more than one (1) hour prior to the pick-up time.

ADVANCE CANCEL: Occurs when a person has reserved a trip and then cancels the trip at least one (1) day prior to the reservation date.

Individuals, their guardian(s) or agency sponsor must cancel trips as soon as they become aware the trip will not be made. Persons who call in less than one (1) hour prior to their scheduled pick-up time to cancel a trip will be informed they will be charged with a no-show and informed of the penalty. If an individual has a pick-up/return trip scheduled and is a noshow on the first trip; the return trip will not be canceled unless the individual calls Votran to cancel the return trip. If the return trip is not canceled by the individual and is a no-show it will be counted as two (2) no-shows for the same day on the individual's record. Persons who are unavailable to make the trip when the driver arrives to pick them up will also be marked as a no-show. Individuals on subscription service (three [3] trips or more per week to the same location) must notify the Votran office if they are not to be picked up.

Trips that are cancelled on the same day that the trip is scheduled, but more than one (1) hour prior to the scheduled pick-up time are classified as same day cancellations. Six (6) same day cancellations in one (1) month will be allowed. Over six (6) will be subject to the same progressive action as a no-show violation.

For individuals who call in a day or more ahead to cancel trips, the trip(s) 
will be made inactive and will be classified as an advance cancellation. Advance cancellations shall be monitored and customers will be notified upon repeated occurrences.

Customers are permitted to have three (3) no-shows within a ninety (90) day period. Customers with no-shows above this level will be added to a watch list and monitored for repeated offenses. Customers with subscription service will have their standing order suspended for a fixed period of time. Customers identified with a pattern of system abuse, will be subject to progressive action as follows:

1. The first offense will result in a suspension of service for two (2) weeks. Votran staff will send a letter notifying the client when they will be suspended.

2. If the person is reinstated to the program and they continue a pattern of abuse, the second suspension will be for thirty (30) days.

3. If the customer is again reinstated and has a third offense, the suspension will be sixty (60) days.

4. Upon the fourth occurrence, the individual's transportation privileges will be terminated permanently.

If the individual responds to any no-show notification and provides acceptable, verifiable evidence that the no-show was due to an unforeseen, unavoidable circumstance or an error in scheduling, the missed trip will not be counted as a no-show or same day cancellation.

\section{VOTRAN CLIENTS ARE ULTIMATELY RESPONSIBLE FOR CANCELLING TRIPS.}

\section{RIGHTS AND RESPONSIBILITIES}

The Florida Commission for the Transportation Disadvantaged has 14 
established the following set of rights and responsibilities for paratransit services such as Votran Gold. Please remember that Votran acts as the CTC for Volusia County.

\section{SAFETY:}

\section{Customers have the right to:}

1. trips in air-conditioned and heated vehicles;

2. safe, clean, properly equipped and smoke-free vehicles;

3. properly fastened seatbelts and/or mobility device tie-downs;

4. vehicle transfer points that are sheltered, secure and safe;

5. a properly identified driver;

6. adequate seating, to include ample space for service animals;

7. assistance in maneuvering mobility devices up and down a maximum of one step;

8. Community Transportation Coordinator (CTC) policy on medical emergency during transport.

\section{Customers are responsible to:}

1. be ready and waiting for the vehicle in a safe location up to one (1) hour prior to your scheduled appointment time;

2. keep seat belts and mobility device tie-downs secure until the vehicle stops;

3. remain seated until the vehicle comes to a complete stop;

4. report any safety hazards;

5. keep wheelchairs or other mobility aids in good condition;

6. not tamper with or operate vehicle equipment;

7. address car-seat provision with the CTC;

8. make CTC aware of customer's physical and/or mental conditions prior to transport; and

9. adhere to policy for violent and/or disruptive behavior. 


\section{COURTESY:}

Customers have the right to:

1. professional, courteous and properly trained drivers;

2. assistance while getting in and out of the vehicle and to the seat; and

3. assistance with as many packages as can be carried by the passenger and the operator in one trip.

\section{Customers are responsible to:}

1. call in trip cancellations at least one (1) hour prior to the scheduled pick-up time to avoid being marked a no-show;

2. inform CTC of all pertinent information regarding the trip;

3. present the correct fare;

4. be ready at the time of pick-up; and

5. ensure personal hygiene.

\section{COMPLAINTS:}

Customers have the right to:

1. file complaints without fear of retaliation;

2. prompt investigations and effective resolutions; and

3. current and complete program information.

\section{Customers are responsible to:}

1. file complaints in a timely manner, providing the CTC with pertinent information. 


\section{SERVICE:}

\section{Customers have the right to:}

1. pick-ups within the established one (1) hour pick-up window (two hours for trips between service areas);

2. expect the driver to wait up to five minutes;

3. toll-free accessibility to the CTC;

4. be delivered to an appointment on time;

5. the CTC's policy on standing orders; and

6. the CTC's policy on no-shows.

\section{Customers are responsible to:}

1. advise the reservationist of appointment times;

2. accept a shared-ride service;

3. schedule trip requests at least one day in advance; and

4. provide own wheelchair and/or escort.

\section{What other responsibilities do I have as a Votran passenger?}

\section{SAFETY}

Passengers are responsible for observing safety rules including use of seat belts, not standing when bus is in motion and waiting for driver to assist them on and off the bus.

Florida State law has determined that all passengers on Paratransit vehicles MUST WEAR SEAT BELTS. A passenger who refuses to remain seated with the seat belt in place will be denied service. If you have medical documentation stating that the use of seat belts may be detrimental to your health, the seat belt regulation will be waived. Please inform the reservationist of your situation when you schedule your first trip, you will be required to provide Votran with written documentation to have the seat belt requirement waived. 


\section{APPROPRIATE BEHAVIOR}

Passengers may not eat, drink, smoke or spit on the bus. Passengers are responsible for being considerate of other passengers in sharing rides, practicing good personal hygiene and to refrain from excessive noise, constantly changing seats, throwing objects, fighting, sticking heads or arms out the windows, lewd behavior and speech, etc. This behavior will not be tolerated.

In accordance with Votran Policy, service may be terminated due to threats, violent or abusive treatment toward the provider or other passengers. Service may be refused if a passenger engages in violent, seriously disruptive or illegal conduct. Seriously disruptive conduct does not include behavior or appearance that only offends, annoys, or inconveniences other riders or employees.

When it has been determined by the Votran Operations Manager that suspension will be initiated, communication of the suspension of service will be made by phone and/or mail to the Passenger or Parent/Guardian of Passenger with a copy to the appropriate agency (if applicable).

\section{MEDICAID PROGRAM}

Trips are provided to Medicaid recipients who have a valid Medicaid recipient number and will be receiving a covered service. Please note that transportation is not authorized for all Medicaid programs. Please check with your case manager or a Votran staff member to verify your eligibility status.

Medicaid recipients (with certain exceptions) will be charged a copayment for each one-way trip. This is a requirement of Florida Law. If you are riding under the Medicaid Program, you will be charged a copayment unless the Reservationist tells you otherwise.

Out of area (outside Volusia County) trips are limited. Out of area trips must be scheduled at least one (1) week in advance. All out of area trips require medical necessity verification from your doctor. This documentation must be faxed or mailed to Votran before the trip can be 
scheduled. If the proper documentation is not received Votran staff will not be able to schedule the trip. Once the trip is scheduled it is advisable to call Votran after 3:00 p.m. the day before the trip to find out what time the vehicle will pick you up.

\section{SHARE OF COST}

Some Medicaid clients are subject to meeting a "share of cost" obligation before the cost of services is covered. Customers enrolled in the share of cost program may reserve trips prior to meeting their requirement. However, provision of the trip depends on your share of cost status on the day you will be traveling.

\section{MEDICAID BUS PASS PROGRAM}

You may be eligible for the MEDICAID BUS PASS PROGRAM which allows unlimited rides on our regular fixed route bus system for a small one time cost per month. For more information on the BUS PASS PROGRAM, please call our Customer Service Department.

What if I'm not satisfied with the services provided?

\section{CUSTOMER FEEDBACK}

If you experience a problem with any aspect of the service, you may call or write to Votran's Customer Service Department. Please call (386) 7567496 or (386) $761-7700$ and ask to speak to a Customer Service Representative. To send your complaint in writing, direct your correspondence to:

Votran Customer Service Department 950 Big Tree Road South Daytona, FL 32119

Please include details such as time, date, location and a description of 
the problem you experienced. This will help in determining the appropriate personnel to contact in order to resolve any difficulties you may have as quickly as possible.

If your complaint cannot be resolved, you may obtain information on the grievance process by contacting the Customer Service Manager and requesting a copy of our adopted Grievance Procedure.

OR

You may call the Florida Commission for the Transportation Disadvantaged Ombudsman Hot Line:

1-800-983-2435. 


\section{Acknowledgement of Receipt Form}

The information provided in this guide is an important factor in helping you understand your transportation options on the Votran Gold Service. We encourage you to read it completely and to contact the Customer Service staff if you have any questions regarding the information contained within this booklet.

It's important for Votran staff to know that you have received this User Guide. Please sign you name below, detach this page, and return it to Votran. You will receive one Votran Gold Token as a thank you for completing this form.

$\overline{\text { Customer Signature }} \quad \overline{\text { Date }}$

Printed Name 